Research Article

\title{
Supply Chains Competition under Uncertainty Concerning Player's Strategies and Customer Choice Behavior: A Generalized Nash Game Approach
}

\author{
A. Hafezalkotob and A. Makui \\ Department of Industrial Engineering, Iran University of Science and Technology, \\ Tehran 16184613114, Iran \\ Correspondence should be addressed to A. Hafezalkotob, hafezalkotob@iust.ac.ir
}

Received 23 December 2011; Revised 21 March 2012; Accepted 29 March 2012

Academic Editor: Alex Elias-Zuniga

Copyright (c) 2012 A. Hafezalkotob and A. Makui. This is an open access article distributed under the Creative Commons Attribution License, which permits unrestricted use, distribution, and reproduction in any medium, provided the original work is properly cited.

\begin{abstract}
Decision makers in a supply chain confront two main sources of uncertainty in market environment including uncertainty about customers purchasing behaviors and rival chains strategies. Focusing on competition between two supply chains, it is considered that each customer as an independent player selects products of these chains based on random utility model. Similar to quantal response equilibrium approach, we take account of customer rationality as an exogenous parameter. Moreover, it is assumed that decision makers in a supply chain can perceive an estimation of rival strategies about price and service level formulated in the model by fuzzy strategies. In the competition model, chain's decision makers consider a subjective probability for wining each customer which is formulated by coupled constraints. These constraints connect chains strategies regarding to each customer and yield a generalized Nash equilibrium problem. Since price cutting and increasing service level are main responses to rival supply chain, after calculating optimal strategies, we show that more efficient responses depend on customer preferences.
\end{abstract}

\section{Introduction}

The supply chain (SC) is typically decentralized which implies that participants are independent firms with their own conflicting goals. Collaboration and coordination of these firms will hopefully result in adding benefits [1]. Decision makers in each SC encounter two sources of uncertainty in a market environment. In the real world competition, gaining a clear perception of rival strategies is not often possible for decision makers. That is, the competitor's strategies are sensed with a level of indistinctness and vagueness. On the other hand, precise determination of customer's responses to products is often not possible for 
decision makers in SCs as well. Thus, the second source of uncertainty is related to customers' behaviors and their product selections procedure.

In many practical situations, players share some resources available in limited amount. Moreover, in many real game applications in the economic systems, players expect a minimum level of payoff from actual transactions. Both these situations lead to a feasible set for players' strategies. In the noncooperative game, if each player's feasible strategies depend on the rival players' strategies, we speak of generalized Nash equilibrium problems (GNEPs) [2]. GNEPs have received an increasing amount of attention in recent times because GNEPs naturally arise in modeling of complex and important economic systems [3]. In practical instances of GNEPs, the feasible sets of the players are usually defined by inequality constraints (or coupled constraints). Customer segments can be considered as shared and limited resources among competitive firms in a market. We concentrate on the competition between two independent SCs for winning customer segments of a specific product type. It is assumed that decision makers in each SC consider a minimum probability (risk) of losing each customer segment as a rule. This assumption connects SCs strategies together and results in inequality constraints in the competition model.

In the marketing literature, the concept of competitive responsiveness argues that the changing strategy by one party in a market will be responded by the other competitors, and the elasticity measures capture the effect of competitive reactions [4]. Two distinguishing types exist regarding to competitive reactions: simple or multiple competitive relations. In the simple case, changing in one type of strategy will be responded by a same strategy. For instance, competitors respond to a change in price for a party by changing their prices and to a change in service level by a service level response, and so forth. However, our competition model is consistent with the concept of the multiple competitive reactions (the concept of marketing mix) such that an SC may react to the price change not only by changing its price but also by changing its service level. In the model, the combination of the profit maximization objective and the minimum risk of losing customer constraints specify the efficient reactions against rival chain changing strategies.

Markets often are not homogenous. In the marketing segmentation models, the customers' populations are divided into groups which have similar behaviors and utilities [5]. It is assumed that a market consists of finite and independent customer segments (or customers) that each of them has distinguishing utility and demand function of the products. Therefore, customer and customer segment are used interchangeably throughout the paper. When SCs perceive requirements of various segments, they will focus on satisfying them. Loss of a customer segment causes erosion of market share, which is often dramatic for SCs [6]. On the other hand, by taking the advantage of this concept, managers concentrate on each customer segment attractions to increase their market shares. The risk of losing a customer segment or customer harms the trade of all partners in an SC.

We use fuzzy set theory to deal with vagueness of other competitor strategies. It is assumed that decision makers in an SC can perceive an estimation of rival's strategies about price and service level formulated in the model by fuzzy strategies. Moreover, it is considered that each customer as an independent player selects products of these chains based on random utility model (RUM) [7]. Therefore, we use stochastic programming based on RUM to involve customer selection behavior in the model. Similar to quantal response equilibrium (QRE) approach $[8,9]$, the customer rationality is taken into account. We investigate how customer rationality affects competition between two chains and how this factor influences optimal utilities of chains' products from customer point of view. The integration of fuzzy logic and stochastic programming give the research an original contribution to define SCs 
competition model based on mathematical element of game theory which can manage vagueness and uncertainty of decision makers.

The paper is organized as follows. The literature related to SC competitions, noncooperative fuzzy game, and customer purchasing behaviors are separately reviewed in Section 2. Section 3 includes a discussion of the problem and related notations. Section 4 concerns basic models of competition between two SCs for a single customer segment, then the model is developed for all customer segments in a market. Finally, the paper concludes in Section 5 with the results of the research.

\section{Literature Review}

Several researches reviewed and studied the applications of game theory in order to model conflicting goals in SCs management $[1,10,11]$. Beside competition and collaboration within an SC, in a specific product market, there are some kinds of competition among SCs to attract final customers. Some papers explicitly modeled SCs interactions in a market [12-25].

Bernstein and Federgruen [14] developed a stochastic inventory model for an oligopoly where demand was a function of all retailers' prices and service levels. Three scenarios were studied in the paper: only price competition, simultaneous price and service level competition, and two stage competition. Wu et al. [21] considered two manufactures; each produced a substitutable product and sold it by either a decentralized retail store or an integrated one. The problem was modeled as a price-setting newsvendor. The effects of demand uncertainty as well as product substitutability on SC configuration were also investigated.

Bernstein and Federgruen [15] assumed a general model of two-echelon SCs with several competing retailers served by a common supplier. In the study, the demand of retailers is a stochastic function and depends on all of the firm's strategies. Xiao and Yang [22] developed an information revelation mechanism model of two-echelon SC facing an outside competitor to investigate the effect of the risk-sharing rule on revelation mechanism under demand uncertainty, where the risk sensitivity of the retailer is private information. Furthermore, Xiao and Yang [23] developed a competition model of two SCs to study the optimal decisions of the players under demand uncertainty. They fully analyzed the effect of the retailer risk sensitivity and service investment efficiency on the optimal decisions.

Product price and service level offered by SCs are two significant factors affecting the purchasing decisions of customers [23]. Several papers considered price and service competition [12, 14, 15, 22-26]. Among these researches, Bernstein and Federgruen [14, 15] developed a price and service competition model based on market share computed by attractions and linear demand function, as well. On the other hand, Allon and Federgruen [12] as well as Xiao and Yang [22, 23] proposed models where retailer's demand is a linear combination of product price and service level offered by a retailer and his/her rival retailer. Hafezalkotob et al. [24] investigated a network design problem in a competition of two SCs where uncertain markets' demands depend on price, service level, and marketing expenditure of chains. They assumed the risk of participants is derived from market's demands uncertainty. However, our decision structure in the present paper is different because we assume that decision makers in an SC can perceive an estimation of rival strategies. Hafezalkotob and Makui [25] considered that the risk of losing customers can be defined based on products utility from customers' viewpoint. They proposed a noncooperative competition model between an SC and rival manufacturer to investigate 
trade-offs of responsiveness and efficiency in an SC. They found that the higher the responsiveness to customers' needs, the lower the risk of losing the customers will be. Tsay and Agrawal [26] investigated a one-manufacture and two-retailer SC which offers a common product to customers. The competition between the retailers was modeled based on linear customer demand function in service level and price which each retailer offered to the market. To the best of the authors' knowledge, no research was found in the context of competition among SCs to investigate the risk of SCs with respect to the customers purchasing behavior.

According to this gap in the literature, there are three main contributions in the research. First, we study customers' purchasing behaviors based on random utility of SC's products. The higher the utility of products for the customer, the higher the probability of purchasing will be. Second, by applying RUM, we investigate the effect of customer rationality on SC's competition. Finally, contrary to the literature, we assume the strategies of rival SC are perceived by chain's participants with some degree of uncertainty which are formulated by fuzzy strategies. The related literature to RUM and fuzzy strategies are briefly reviewed through the following subsections.

\subsection{Noncooperative Fuzzy Games}

One of the major deficiencies of the traditional noncooperative game theory is the assumption of all players to be completely aware of all data concerning the game structures [27]. In the real-world circumstances, it often happens that the players are not able to estimate exactly the outcomes of different strategies and/or their preferences of the other players. In other words, each player regularly has a vague and heuristic knowledge of the other players [28]; thus, a level of uncertainty exists about his/her choices. Fuzzy set theory $[29,30]$ is an excellent tool which can be used for softening the crisp noncooperative game theory. The degree of uncertainty in fuzzy set theory represents the value of vagueness of players in the game environment.

Cooperative fuzzy games have been initially introduced by Aubin [31]. Afterward, Butnariu [32-35] for the first time incorporated fuzzy approach into noncooperative games. The work of Butnariu was complemented by other researchers [28, 36-39]. Recently, fuzzy sets approach has been intensively utilized to model noncooperative games in the uncertain environment [27].

In general, there exist two approaches treating to fuzziness in games: the approach based on fuzzy preferences, strategies, and perception or belief of players and the approach based on fuzzy evaluation of the payoffs [27]. In the first approach, the players use partly crisp and partly fuzzy strategies as well as partly crisp and partly fuzzy preferences to play the game. However, the second approach is an extension of the traditional theory of games against nature, and players choose strategies with regard to both the behavior of other players and possible realization of fuzzy parameters of the nature or game situation [40].

Garagic and Cruz [28] developed Nash equilibrium concept for the first approach of games. For a bimatrix game, they used fuzzy control to model situations where each strategy available to the player is defined by a membership function. They illustrated their model for planning and conducting a military operation. Similarly, fuzzy strategies in a noncooperative game are also considered by Song and Kandel [41]. Francesco and Gravio [42] proposed fuzzy logic to represent the characteristic aspect of a bilateral bargaining with incomplete information. Under imperfect information condition, the seller and buyer have 
only imprecise information, preferring to keep private the real value of opportunity cost and acceptable price, respectively. An intermediary repeatedly negotiates with supplier and customer to reach an agreement.

In the real competition among SCs, an agent often is not able to recognize or estimate the precise strategies of other competitors. Generally, noise or vagueness exists about other SCs actions when it comes to decision making. We use fuzzy set theory to deal with the uncertainty in regard to rival SC's strategies.

\subsection{Customer Behavior and Brand Choice Models}

Customer behavior theory investigates the customers purchasing behavior and their decision to buy or ignore a product. Similarly, the main aim of brand choice models is to answer the question that why customers shift from one brand to another and in which fashion the changes in brands' market shares are occurring [43]. Therefore, these models analyze the previous data to estimate the customer's choice process. A well-known brand choice model is RUM or in its most used form, the multinomial logit model (MNL) which was developed by McFadden [7]. The MNL market share represents an aggregate concept that the consumer choice-based utility theory may serve as a foundation for individual rational decision making [44]. Cooper [45] investigated the relationship between different market share models and individual choice probabilities. Choice models founded on RUM make a connection between the attributes that characterize different competing products to the probability that they will be selected by customers [46].

According to the structure defined by the theory of RUM [47], the utility of customer $i$ obtain from product $j\left(V_{i j}\right)$ is made of two parts, one deterministic $U_{i j}$ and the other random $\varepsilon_{i j}$. The deterministic part can be considered as a function of a $\left\{X_{k j}\right\}_{k \in K}$ of attributes that characterize the choice procedure for customer $i$. The random component is stochastic and reflects the idiosyncrasies of customer $i$ in taste for product $j$. Taking into account additive structure for the deterministic part, the customer utility function can be written as follows:

$$
V_{i j}=U_{i j}+\varepsilon_{i j}=\theta_{0 j}+\sum_{k \in K} \theta_{k i j} X_{k j}+\varepsilon_{i j}
$$

where $\left\{\theta_{k i j}\right\}_{k \in K}$ represents the response parameters for attributes of set $K$, and $\theta_{0 j}$ denotes an additional parameter related to the intrinsic utility of product of brand $j$. The customer chooses the alternative which maximizes the utility. Therefore, the probability $P_{i}\left(j \mid \theta_{0}, \theta_{k i j}\right)$ of customer $i$ selecting product of brand $j$ from set $M$ of possible products (where $n$ stands for the number of elements in set $M$ ) is as follows:

$$
P_{i}\left(j \mid \theta_{0}, \theta\right)=P\left(V_{i j} \geq V_{i m} \forall m \in M\right)=P\left(\varepsilon_{i j} \leq U_{i j}-U_{i m}+\varepsilon_{i m} \forall m \in M\right) .
$$

Similar to the approach of logistic quintal response equilibria (Logistic-QRE) introduced by McKelvey and Palfrey $[8,9]$, we concentrate on a particular version of the RUM, where each $\varepsilon_{i j}$ is dependently and identically distributed according to the type I extreme value (or Weibull) distribution with cumulative density $F\left(\varepsilon_{i j}\right)=\exp \left(-\exp \left(-\tau \varepsilon_{i j}\right)\right)$. This distribution has a variance of $\pi^{2} / 6 \tau^{2}$; therefore, the parameter $\tau$ determines the 
precision of $F$. McFadden [7] showed that this distribution function yields the following choice probability

$$
P_{i}\left(j \mid \theta_{0}, \theta\right)=\frac{\exp \left(\tau U_{i j}\right)}{\sum_{m \in M} \exp \left(\tau U_{i m}\right)}=\frac{\exp \left(\tau\left(\theta_{0 j}+\sum_{k \in K} \theta_{k i j} X_{k j}\right)\right)}{\sum_{m \in M} \exp \left(\tau\left(\theta_{0 m}+\sum_{k \in K} \theta_{k i m} X_{k m}\right)\right)} .
$$

With having samples data of each customer segment, the response parameters can be computed by maximum likelihood estimation [48].

QRE model has recently attracted a great deal of attention. The main motivation of this model is assuming that players are not "perfectly rational." Instead, their choices are noisy, and strategies with higher utility are chosen with higher probability [49]. Many experimental results showed that partial rationality of players modeled by QRE can account for players' behavior in the real situations [8]. One of the particular aspects of the logit QRE is nonnegative parameter $\tau$ which can be considered as the rationality parameter. When $\tau \rightarrow \infty$, player becomes "perfectly rational"; therefore, he/she certainly chooses the most favorable alternative. As this parameter declines, the rationality of the player reduces and his/her choice becomes increasingly based on randomness. $\tau \rightarrow 0$ represents that the player is "completely irrational," and he/she does not distinguish favorable products. We apply this approach for customer (or customer segment) $i$; thus, it can be concluded that with growing parameter $\tau$, the customer is more responsive to deterministic part of the utility. Therefore, he/she selects more favorable product with higher probability. Obviously, the value 1 for the parameter provides the RUM introduced by McFadden [7], and $\tau=0$ yields $P_{i}\left(j \mid \theta_{0}, \theta_{k i j}\right)=1 / n$ for all $j$, as well.

\section{Problem Description and Notation}

Two SCs are considered that each is comprised of one manufacturer and one retailer. SCs compete for customer segments in the market. Each SC only provides a single type of product for customers. These products are completely substitutive and differ only in price and offered service levels by retailers.

The competition between two SCs constitutes a noncooperative game to attract customer segments. Due to assumption of independency of customer segments, the competition between retailers can be considered for each segment separately. Considering a minimum acceptable risk of losing each customer segment, decision makers of both SCs attempt to raise possible profit from selling products to the market. The noncooperative game among SCs involves that they simultaneously declare price and service level to the customers. On the other hand, the customer selects favorable products with higher probability.

\subsection{Assumptions}

\subsubsection{Uncertainty concerning Customers' Behaviors}

Customers independently choose products of SCs based on utility maximization. Their behaviors conform to the RUM assumptions introduced by McFadden [7]. The random component of utility of each customer segment is not revealed to decision makers of SCs. Nevertheless, this component is identically distributed according to the type I extreme value (or Weibull). The deterministic parts of the customers' utilities are common knowledge for 
all decision makers. The RUM model has been widely employed to investigate customer preferences in many industries such as food [50], automotive [51], and electronics industries [52].

\subsubsection{Customer Rationality}

Several economics models assume that humans are on average rational due to finite resources available for making decisions [53]. Similar to Logit-QRE approach [8, 9], we assume that customers as players are partially rational. The rationality is indicated by parameter $\tau$ in the RUM of customer behavior. Our assumption about partial (bounded) rationality of customer is more general and realistic than prefect rationality assumption.

\subsubsection{Customer Demand}

When a customer segment selects one of the SCs products, his/her demand is proportional to the offered price and service level. Several researchers investigated price and service level impacts on customers' demand and purchasing behavior in oligopolistic markets $[15,23,24]$.

\subsubsection{Uncertainty concerning Competitor Strategies}

Each agent in an SC perceives the price and service level of the other competitor chain with a noise and vagueness. Similar to fuzzy strategies introduced by Garagic and Cruz, [28], we assume that fuzzy price and service level strategies of rival chain are $L-R$ type fuzzy numbers. Fuzzy-based game theory was also investigated by some researchers in oligopolistic markets when vagueness exists about competitors $[54,55]$.

\subsubsection{Independent Strategies for Customers}

In the real markets, customers are almost independent when there are weak social relationships among them. Bekal et al. [56] considered customers' independency when they were sufficiently geographically dispersed. For independent customers, a retailer is able to pursue customer-specific strategies.

\subsubsection{Maximum Risk of Supply Chains}

Decision makers in each SC consider a minimum probability for attracting each customer segment (or equivalently, they take account of a maximum risk of losing each segment). That is to say, the decision makers do not permit their rival chain to reduce the probability of attracting customer segment $i$ lower than this limit. In the case of two echelons SCs, manufacturer and his/her retailer cooperatively determine this risk based on the importance and value of each customer segment for SC. Maximum acceptable risk condition associates chain's strategies with the rival ones. This condition involves considering inequality constraints (coupled constraints) in the problem which leads to a GNEP. 


\subsection{Input Parameters}

Assume that SC $j$ offers product type $j$ to customer segment $i$. Furthermore, $M_{j}$ and $R_{j}$ denote manufacturer and retailer in $j$ th SC, respectively.

$\theta_{0 j}$ : the normalized attraction denotes intrinsic utility of product $j$.

$\theta_{1 i j}$ : the response parameter of customer segment $i$ th for price of product $j,\left(\theta_{1 i j}>0\right)$.

$\theta_{2 i j}$ : the response parameter of customer segment $i$ th for service level offered by SC $j$, $\left(\theta_{2 i j}>0\right)$.

$\tau_{i}$ : the rationality parameter of customer segment $i,\left(\tau_{i}>0\right)$.

$\alpha_{i}$ : the base demand of customer segment $i,\left(\alpha_{i}>0\right)$.

$\beta_{i}$ : the demand sensitivity of customer segment $i$ to offered service level, $\left(\beta_{i}>0\right)$.

$\gamma_{i}$ : the demand sensitivity of customer segment $i$ to product price, $\left(\gamma_{i}>0\right)$.

$c_{M_{j}}$ : the unit production cost of manufacturer $j, j=1,2,\left(c_{M_{j}} \geq 0\right)$.

$\eta_{R_{j}}$ : the service investment efficiency coefficient of retailer $j, j=1,2$. The larger the coefficient, the lower the service investment efficiency $\left(1 / \eta_{R_{j}}\right)$ of retailer $i$ will be, $\left(\eta_{R_{j}}>0\right)$.

$\phi_{i j}$ : the maximum acceptable risk of losing customer segment $i$ for decision makers in SC $j$, equivalently $1-\phi_{i j}$ represents the minimum acceptable probability of attracting customer segment $i,\left(0 \leq \phi_{i j} \leq 1\right)$.

$\mathrm{FC}_{z}$ : the fixed operation cost of players $z, z=R_{1}, R_{2}, M_{1}, M_{2},\left(F C_{z} \geq 0\right)$.

$\mu_{\tilde{P}_{i j-}}\left(P_{i j-}\right)$ : the fuzzy membership function corresponding to the vagueness of SC $j$ about the price of product $j$ - offered to customer segment $i$ which is an $L-R$ type fuzzy number $\left(P_{i j-}, P_{i j-^{-}}^{-} P_{i j-}^{+}\right)_{L_{P_{i j-}^{j}} R_{P_{i j-}^{j}}}$.

$\mu_{\widetilde{S}_{R_{j-i}}}(y)$ : the fuzzy membership function corresponding to the vagueness of SC $j$ about the service level of retailer $j$-offered to customer segment $i$ which is an $L-R$ type fuzzy number $\left(S_{R_{j-i},}, S_{R_{j-i},}^{-} S_{R_{j-i} i}^{+}\right)_{L_{S_{i j-}^{j}} R_{S_{i j-}^{j}}},\left(S_{R_{j-i}}^{-} S_{R_{j-i}}^{+} \geq 0\right)$.

Note that $j$ - represents the rival SC. For instance, $\mu_{\tilde{S}_{R_{1} 3}^{2}}(y)=\left(S_{R_{1} 3}, 3,7\right)_{L_{S_{R_{1}}^{2}} R_{S_{R_{1} 3}^{2}}}$ states the vagueness of decision makers in chain 2 about the service level of retailer 1 offered to the 3rd customer segment.

\subsection{Decision Variables}

$w_{M_{j}}$ : the wholesale price of manufacturer $j$ offered to his/her retailer, $j=1,2,\left(w_{M_{j}} \geq\right.$ $\left.c_{M_{j}}\right)$.

$m_{R_{j} i}:$ the profit margin of retailer $j$ from selling product to customer segment $i, j=1,2$, $\left(m_{R_{j} i} \geq 0\right)$.

$P_{i j}$ : the retail price of retailer $j$ offered to customer segment $i, j=1,2$; thus, we have $P_{i j}=w_{M_{j}}+m_{R_{j}}$.

$S_{R_{j}}$ : the service level of retailer $j$ offered to customer segment $i, j=1,2\left(S_{R_{j} i} \geq 0\right)$. 


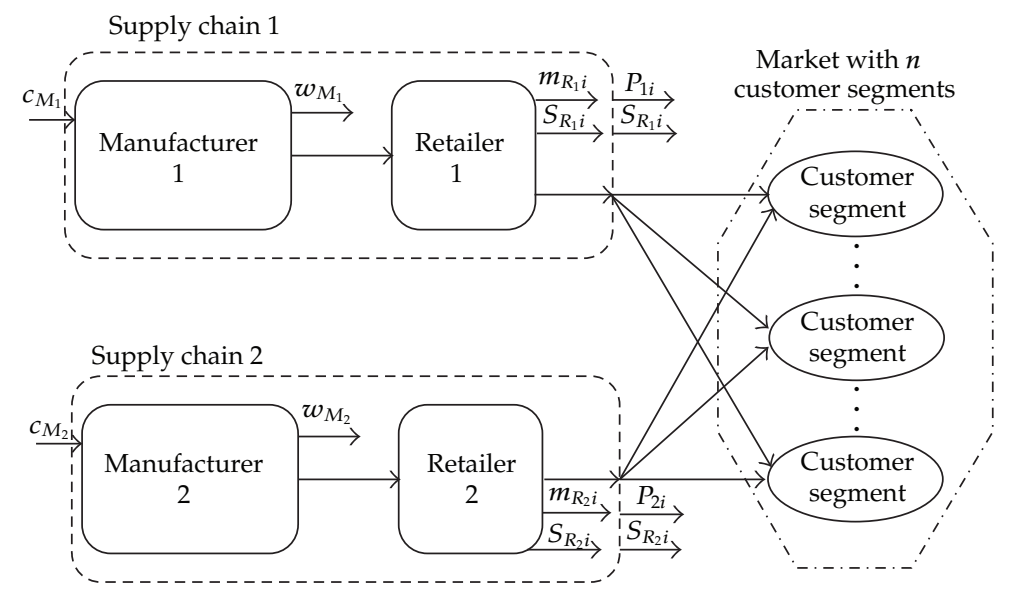

Figure 1: SCs competition schema for the customer segments.

In SC $j$, the manufacturer decides on wholesale price $w_{M_{j}}$, and the retailer determines retail price $P_{i j}$ as well as service level investment $S_{R_{j} i}$ for each customer segment. Figure 1 illustrates the competition schema between two SCs.

\section{The Basics Models}

For the purpose of model explanation, we first consider the competition between SCs for a single customer segment; afterwards, the model will be extended for $n$ customer segments in a market.

\subsection{Manufacturers Problem for a Single Customer Segment}

Losing each customer segment diminishes market share which is often horrible for all partners in an SC. Although partners of an SC compete to gain more profit, they need to maintain a level of cooperation to sell product to the customer segments in a competitive market. The manufacturer in $j$ th SC attempts to increase possible profit with considering a minimum probability of selling products of SC to customer $i$. Thus, manufacturer $j$ considers the following problem:

$$
\max _{w_{M_{j}}} E\left(\pi_{M_{j}}\right)=\left(1-\phi_{i j}\right)\left(w_{M_{j}}-c_{M_{j}}\right)\left(\alpha_{i}-\gamma P_{i j}+\beta S_{R_{j} i}\right)-\mathrm{FC}_{M_{j}}
$$

subject to

$$
\begin{gathered}
P_{i}\left(j \mid \theta_{0 j}, \theta_{k i j}\right)=\frac{\exp \left(\tau_{i}\left(\theta_{0 j}-\theta_{1 i j} P_{i j}+\theta_{2 i j} S_{R_{j} i}\right)\right)}{\exp \left(\tau_{i}\left(\theta_{0 j}-\theta_{1 i j} P_{i j}+\theta_{2 i j} S_{R_{j} i}\right)\right)+\exp \left(\tau_{i}\left(\theta_{0 j-}-\theta_{1 i j-} \widetilde{P}_{i j-}+\theta_{2 i j-} \widetilde{S}_{R_{j-i}}\right)\right)} \geq 1-\phi_{i j}, \\
P_{i j}=w_{M_{j}}+m_{R_{j} i},
\end{gathered}
$$


where $1-\phi_{i j}$ is a minimum probability which is acceptable for managers of SC $j$ to sell its products to customer segment $i$. By applying maximin concept [57], manufacturer $j$ in objective function (4.1) decides on wholesale price to maximize the minimum possible profit from selling products to customer segment $i$. Since the exact strategies of the rival SC are not revealed for manufacturer $j$, he makes his/her decision based on an estimation of rival price $\left(\widetilde{P}_{i j-}\right)$ and service level $\left(\widetilde{S}_{R_{j-i}}\right)$. Taking the RUM into account for the behavior of customer segment $i$, constraint (4.2) ensures that the probability of selling products to customer segment $i$ is higher than the minimum acceptable probability $1-\phi_{i j}$. Combination of objective function (4.1) and constraint (4.2) expresses that the manufacturer relates his possible profit from selling products to the customer purchasing decisions. On the other hand, these decisions depend upon the rival strategies which only estimations of them are available for the manufacturer. The manufacturer problem is a nonlinear GNEP which is not appropriate for the optimization. Lemmas 4.1 and 4.2 can be applied for linearizing the problem.

Lemma 4.1. By considering $\delta$ level cut concept for fuzzy constraint [58, 59], constraint (4.2) will be equivalent to

$$
\theta_{0 j}-\theta_{0 j-}-\theta_{1 i j} P_{i j}+\theta_{1 i j-} P_{i j-}+\theta_{2 i j} S_{i j}-\theta_{2 i j-} S_{2 i j-} \geq \ln \left(\frac{1-\phi_{i j}}{\phi_{i j}}\right)^{1 / \tau_{i}}-\left(1-\delta_{i j-}^{j}\right) \rho_{i j-\prime}^{j}
$$

where $\rho_{i j-}^{j}=\theta_{i j 1} P_{i j-}^{+}+\theta_{i j 2} S_{R_{j-i}}^{-}$and $0 \leq \delta_{i j-}^{j} \leq 1$.

Proofs of all propositions and lemmas are given in the Appendix. In Lemma 4.1, $\delta_{i j-}^{j}$ level cut can be interpreted as a confidence level of decision makers of SC $j$ in the strategies of SC $j$ - corresponding to customer segment $i$. Therefore, in constraint (4.4), $\delta_{i j-}^{j}$ equals to 1 means that DMs of SC $j$ are sure that the probability of attracting customer $i$ is higher than $1-\phi_{i j}$. This confidence level declines as $\delta_{i j-}^{j}$ approaches zero. It is straightforward from the right hand side of constraint (4.4) that the uncertainty about rival strategies measured by the confidence level reduces the minimum probability of attracting the customer segment. Thus, in objective function (4.1), $1-\phi_{i j}$ has to be changed with respect to the confidence level. In Lemma 4.2, the minimum probability of attracting customer segment $i$ is updated.

Lemma 4.2. When vagueness about competitor's strategies exists, the minimum probability of attracting customer segment $j$, that is, $1-\phi_{i j}$, is changed as follows:

$$
1-\phi_{i j}^{\prime}=k_{i j}\left(1-\phi_{i j}\right)
$$

where $k_{i j}=\left[1-\phi_{i j}+\phi_{i j} \exp \left(\rho_{i j-}^{j} \tau_{i}\left(1-\delta_{i j-}^{j}\right)\right)\right]^{-1}$.

Note that in the case of absolute confidence, or no vagueness about competitor strategies, or quite irrational customer (i.e., $\delta_{i j-}^{j}=1$ or $\rho_{i j-}^{j}=0$ or $\tau_{i}=0$ ), we have $1-\phi_{i j}^{\prime}=1-\phi_{i j}$. 
By applying the results of Lemmas 4.1 and 4.2 to manufacturer problem (4.1)-(4.3), the linear GNEP is as follows:

$$
\max _{w_{M_{j}}} E\left(\pi_{M_{j}}\right)=k_{i j}\left(1-\phi_{i j}\right)\left(w_{M_{j}}-c_{M_{j}}\right)\left[\alpha_{i}-\gamma_{i}\left(w_{M_{j}}+m_{R_{j} i}\right)+\beta_{i} S_{R_{j} i}\right]-\mathrm{FC}_{M_{j}},
$$

subject to

$$
\theta_{0 j}-\theta_{0 j-}-\theta_{1 i j}\left(w_{M_{j}}+m_{R_{j} i}\right)+\theta_{1 i j-} P_{i j-}+\theta_{2 i j} S_{R_{j} i}-\theta_{2 i j-} S_{R_{j-i}} \geq \frac{1}{\tau_{i}} \ln \left(\frac{1-\phi_{i j}}{\phi_{i j}}\right)-\left(1-\delta_{i j-}^{j}\right) \rho_{i j-}^{j} .
$$

\subsection{Retailers Problem for a Single Customer Segment $i$}

Now we study the retailer problem in the case of a single customer segment $i$. Retailer $j$ determines the margin profit as well as service level. Similar to the manufacturer, the retailer assumes a lower bound for the probability of selling products to the customer segment. The retailer maximizes the minimum possible profit from trade with the customer segment. Therefore, the following model can be considered for the retailer

$$
\max _{m_{R_{j}}, S_{R_{j} i}} E\left(\pi_{R_{j}}\right)=\left(1-\phi_{i j}\right)\left(m_{R_{j}}\right)\left(\alpha_{i}-\gamma_{i} P_{i j}+\beta_{i} S_{R_{j} i}\right)-\frac{1}{2} \eta_{R_{j}} S_{R_{j} i}{ }^{2}-\mathrm{FC}_{R_{j}}
$$

subject to constraints (4.2) and (4.3).

As suggested in the extensive literature of SC game models [22, 23, 26, 60], we assume that when a player provides service level $S_{R_{j} i}$, the service cost of the player is $0.5 \eta_{R_{j}} S_{R_{j}}{ }^{2}$, that is, improving service level has a diminishing return on service expenditure. Both of the chain's partners by choosing proper value for their controllable variables endeavor to maintain this probability within an acceptable limit. The retailer problem is also a nonlinear GNEP which is not appropriate for computing Nash equilibrium. By applying Lemmas 4.1 and 4.2 for the retailer problem, we have

$$
\max _{m_{R_{j}}, S_{R_{j}}} E\left(\pi_{R_{j}}\right)=k_{i j}\left(1-\phi_{i j}\right)\left(m_{R_{j} i}\right)\left[\alpha_{i}-\gamma_{i}\left(w_{M_{j}}+m_{R_{j} i}\right)+\beta_{i} S_{R_{j}}\right]-\frac{1}{2} \eta_{R_{j}} S_{R_{j}}{ }^{2}-\mathrm{FC}_{R_{j}}
$$

subject to constraint (4.7).

Constraint (4.7) is a "coupled constraint" which relates SCs' strategies to rival ones to guarantee the minimum probability of attracting customer segment $i$. Therefore, manufacturer profit (4.6) and retailer profit (4.9) along with coupled constraint (4.7) constitute GNEPs. To solve these problems, we associate a multiplier $\lambda_{i j}$ with coupled constraint (4.7). Hessian matrix of $E\left(\pi_{R_{j}}\right)$ is

$$
\mathbf{H}_{R_{j}}=\left[\begin{array}{cc}
-2 k_{i j}\left(1-\phi_{i j}\right) \gamma_{i} & k_{i j}\left(1-\phi_{i j}\right) \beta_{i} \\
k_{i j}\left(1-\phi_{i j}\right) \beta_{i} & -\eta_{R_{j}}
\end{array}\right]
$$


The expected profit $E\left(\pi_{R_{j}}\right)$ is a concave function on $\left(m_{R_{j} i}, S_{R_{j} i}\right)$ if and only if the Hessian matrix is negatively definite [61]. Let us define $B_{i j}^{\prime}=2 \gamma_{i} \eta_{R_{j}}-\beta_{i}^{2}$ and $B_{i j}=3 \gamma_{i} \eta_{R_{j}}-$ $k_{i j}\left(1-\phi_{i j}\right) \beta_{i}^{2}$. From the manufacturer and retailer problems, we drive the following.

Proposition 4.3. If $B_{i j}^{\prime}>0$, then the optimum values for wholesale price of the manufacturer, as well as the marginal profit and service level of the retailer, are as follows:

(i) if $\lambda_{i j}=0$, then one has

$$
\begin{gathered}
m_{R_{j} i}^{*}=\frac{\left(\alpha_{i}-\gamma_{i} c_{M_{j}}\right) \eta_{R_{j}}}{B_{i j}}, \\
w_{M_{j}}^{*}=c_{M_{j}}+\frac{\left(\alpha_{i}-\gamma_{i} c_{M_{j}}\right) \eta_{R_{j}}}{B_{i j}}, \\
S_{R_{j} i}^{*}=\frac{\beta_{i} k_{i j}\left(1-\phi_{i j}\right)\left(\alpha_{i}-\gamma_{i} c_{M_{j}}\right)}{B_{i j}},
\end{gathered}
$$

(ii) if $\lambda_{i j}=\Lambda_{i j} \neq 0$, then one has

$$
\begin{aligned}
m_{R_{j} i}^{*}= & \frac{k_{i j}\left(1-\phi_{i j}\right) \theta_{2 i j}^{2}\left(\alpha_{i}-\gamma_{i} c_{M_{j}}\right)}{2 \theta_{1 i j} E_{i j}-\theta_{2 i j} k_{i j}\left(1-\phi_{i j}\right) F_{i j}} \\
& +\frac{E_{i j}\left[-\theta_{1 i j} c_{M_{j}}+\theta_{0 j}-\theta_{0 j-}-Q_{i j}+\theta_{1 i j-}\left(w_{M_{j-}}+m_{R_{j-}}\right)-\theta_{2 i j-} S_{R_{j-}}\right]}{2 \theta_{1 i j} E_{i j}-\theta_{2 i j} k_{i j}\left(1-\phi_{i j}\right) F_{i j}}, \\
w_{M_{j}}^{*}= & c_{M_{j}}+\frac{k_{i j}\left(1-\phi_{i j}\right) \theta_{2 i j}^{2}\left(\alpha_{i}-\gamma_{i} c_{M_{j}}\right)}{2 \theta_{1 i j} E_{i j}-\theta_{2 i j} k_{i j}\left(1-\phi_{i j}\right) F_{i j}} \\
& +\frac{E_{i j}\left[-\theta_{1 i j} c_{M_{j}}+\theta_{0 j}-\theta_{0 j-}-Q_{i j}+\theta_{1 i j-}\left(w_{M_{j-}}+m_{R_{j-} i}\right)-\theta_{2 i j-} S_{R_{j-}}\right]}{2 \theta_{1 i j} E_{i j}-\theta_{2 i j} k_{i j}\left(1-\phi_{i j}\right) F_{i j}} \\
S_{R_{j} i}^{*}= & \frac{k_{i j}\left(1-\phi_{i j}\right)}{2 \theta_{1 i j} E_{i j}-\theta_{2 i j} k_{i j}\left(1-\phi_{i j}\right) F_{i j}} \\
& \times\left[2 \theta_{1 i j} \theta_{2 i j}\left(\alpha_{i}-\gamma_{i} c_{M_{j}}\right)\right. \\
& \left.+F_{i j}\left[-\theta_{1 i j} c_{M_{j}}+\theta_{0 j}-\theta_{0 j-}-Q_{i j}+\theta_{1 i j-}\left(w_{M_{j-}}+m_{R_{j-i}}\right)-\theta_{2 i j-} S_{R_{j-i}}\right]\right]
\end{aligned}
$$




$$
\begin{aligned}
\Lambda_{i j}= & \frac{k_{i j}\left(1-\phi_{i j}\right)}{2 \theta_{1 i j} E_{i j}-\theta_{2 i j} k_{i j}\left(1-\phi_{i j}\right) F_{i j}} \\
& \times\left[\left(\alpha_{i}-\gamma_{i} c_{M_{j}}\right)\left[2 \eta_{R_{j}} \theta_{1 i j}-k_{i j}\left(1-\phi_{i j}\right) \beta_{i} \theta_{2 i j}\right]\right. \\
& \left.\quad-B_{i j}\left[-\theta_{1 i j} c_{M_{j}}+\theta_{0 j}-\theta_{0 j-}-Q_{i j}+\theta_{1 i j-}\left(w_{M_{j-}}+m_{R_{j-i}}\right)-\theta_{2 i j-} S_{R_{j-}}\right]\right],
\end{aligned}
$$

where $E_{i j}=\theta_{1 i j} \eta_{R_{j}}-\theta_{2 i j} k_{i j}\left(1-\phi_{i j}\right) \beta_{i}, F_{i j}=\theta_{1 i j} \beta_{i}-3 \theta_{2 i j} \gamma_{i}$, and $Q_{i j}=\left(1 / \tau_{i}\right) \ln ((1-$ $\left.\left.\phi_{i j}\right) / \phi_{i j}\right)-\left(1-\delta_{i j-}^{j}\right) \rho_{i j-}^{j}$.

Retailer $j$ excessively invests in service if $B_{i j}^{\prime}<0$, which incurs a negative profit to him. The condition $B_{i j}^{\prime}>0$ means that the service investment should not be too inexpensive, which is consistent with those considered in $[23,26,53]$. Therefore, we assume that $B_{i j}^{\prime}>0$ throughout this paper. Moreover, the negative values for optimal profit margin and service level are not feasible for the retailer, that is, $m_{R_{j} i}^{*} S_{R_{j} i}^{*}>0$. Since from $B_{i j}^{\prime}>0$ and $0 \leq k_{i j} \leq 1$, it follows that $B_{i j}>0$, and we assume that $\alpha_{i}>\gamma_{i} c_{M_{j}}$ to ensure $m_{R_{j} i}^{*} S_{R_{j} i}^{*}>0$. The condition $\alpha_{i}>\gamma_{i} c_{M_{j}}$ indicates that unit production cost should not be too high. The multiplier $\lambda_{i j}$ associated with KKT condition may be thought as a shadow price for coupled constraint (4.7); furthermore, complementary slackness condition holds for the multiplier and the coupled constraint. That is to say, coupled constraint (4.7) is binding if $\lambda_{i j}=\Lambda_{i j} \neq 0$.

Proposition 4.3 presents the optimal strategies of SC $j$ regarding customer segment $i$ which depends on the strategies of rival chain $(j-)$. In other words, if $X_{i j}$ and $X_{i j-}$ denote vectors of the decisions or strategy variables of SCs $j$ and its rival $j-$, respectively, then the optimal values in Proposition 4.3 are $X_{i j}^{*}\left(X_{i j-}\right)$. This proposition gives the following insights.

(i) For a single customer segment $i$, the optimal marginal profits of manufacturer and retailer are equal. Therefore, if $P_{i j}^{*}-c_{M_{j}}$ is the optimal profit margin of a product unit for $\mathrm{SC} j$, it is optimal that the manufacturer and the retailer consent to the equal profit margin $\left(P_{i j}^{*}-c_{M_{j}}\right) / 2$. This situation holds for both the conditions $\lambda_{i j}=0$ and $\lambda_{i j} \neq 0$.

(ii) The $\lambda_{i j}=0$ states that the SC $j$ th will sell product to customer segment $i$ with probability higher than the least acceptable probability, that is, $P_{i}\left(j \mid \theta_{0 j}, \theta_{k i j}\right) \geq$ $1-\phi_{i j}$. In this situation, the rival chain strategies (i.e., $X_{i j-}$ ) have no effects on the optimal price and service level of SC $j$.

(iii) Adversely, $\lambda_{i j}=\Lambda_{i j} \neq 0$ expresses that the probability of attracting customer segment $i$ by SC $j$ th decreases to the threshold of the minimum acceptable probability, that is, $P_{i}\left(j \mid \theta_{0 j}, \theta_{k i j}\right)=1-\phi_{i j}$. In this situation, SC's strategies depend on the rival strategies. In other words, any variation in price and service level of the rival needs to be responded by the SC to ensure the least probability of selling products to customer segment $i$. In Proposition 4.4, the SC responses to variations in strategies of the rival are investigated. 
Proposition 4.4. In the case of $\lambda_{i j}=\Lambda_{i j} \neq 0$, for the optimal strategies values in Proposition 4.3, one has

(1) $\partial m_{R_{i} i}^{*} / \partial w_{M_{j-}}=\partial m_{R_{j} i}^{*} / \partial m_{R_{j-i}}=\partial w_{M_{j}}^{*} / \partial w_{M_{j-}}=\partial w_{M_{j}}^{*} / \partial m_{R_{j-i}}=E_{i j} \theta_{2 i j-} /\left[2 \theta_{1 i j} E_{i j}-\right.$ $\left.\theta_{2 i j} k_{i j}\left(1-\phi_{i j}\right) F_{i j}\right], \partial m_{R_{j} i}^{*} / \partial S_{R_{j-i}}=\partial w_{M_{j}}^{*} / \partial S_{R_{j-i}}=-E_{i j} \theta_{2 i j-} /\left[2 \theta_{1 i j} E_{i j}-\theta_{2 i j} k_{i j}(1-\right.$ $\left.\left.\phi_{i j}\right) F_{i j}\right]$,

(2) $\partial S_{R_{i}}^{*} / \partial w_{M_{j-}}=\partial S_{R_{i} i}^{*} / \partial m_{R_{j-i}}=\left[k_{i j}\left(1-\phi_{i j}\right) F_{i j} \theta_{1 i j-}\right] /\left[2 \theta_{1 i j} E_{i j}-\theta_{2 i j} k_{i j}\left(1-\phi_{i j}\right) F_{i j}\right]$, $\partial S_{R_{i} i}^{*} / \partial S_{R_{j-i}}=\left[-k_{i j}\left(1-\phi_{i j}\right) F_{i j} \theta_{2 i j-}\right] /\left[2 \theta_{1 i j} E_{i j}-\theta_{2 i j} k_{i j}\left(1-\phi_{i j}\right) F_{i j}\right]$.

Proposition 4.4 analyzes how the optimal wholesale and retail price as well as service level of one SC are affected by the retail price and service level of the rival chain. For instance, assume that the rival retailer decides to reduce $\Delta m_{R_{j-i}}$ from his/her retail price to attract customer segment $i$. From constraint (2.3), it is obvious that the product utility of the rival chain increases $\Delta m_{R_{j-i}} \theta_{1 i j-}$ from the customer point of view. The SC $j$ considers the following changes in its optimal strategies to react to his/her rival:

$$
\begin{aligned}
\Delta m_{R_{j} i} & =\frac{E_{i j} \theta_{1 i j-}}{2 \theta_{1 i j} E_{i j}-\theta_{2 i j} k_{i j}\left(1-\phi_{i j}\right) F_{i j}}\left(-\Delta m_{R_{j-i}}\right), \\
\Delta w_{M_{j}} & =\frac{E_{i j} \theta_{1 i j-}}{2 \theta_{1 i j} E_{i j}-\theta_{2 i j} k_{i j}\left(1-\phi_{i j}\right) F_{i j}}\left(-\Delta m_{R_{j-i}}\right), \\
\Delta S_{R_{j}} & =\frac{-k_{i j}\left(1-\phi_{i j}\right) F_{i j} \theta_{2 i j-}}{2 \theta_{1 i j} E_{i j}-\theta_{2 i j} k_{i j}\left(1-\phi_{i j}\right) F_{i j}}\left(-\Delta m_{R_{j-i}}\right) .
\end{aligned}
$$
follows:

Therefore, the product utility of SC increases from the customer's viewpoint as

$$
\Delta U_{i j}=-\theta_{1 i j}\left(\Delta m_{R_{j} i}+\Delta w_{M_{j}}\right)+\theta_{2 i j}\left(\Delta S_{R_{j}}\right)=\Delta m_{R_{j-i}} \theta_{1 i j-}=\Delta U_{i j-} .
$$

In other words, SC $j$ th increases its product utility just equal to the rival's one to hold coupled constraint (4.2), that is, if $\lambda_{i j}=\Lambda_{i j} \neq 0$, then $\Delta U_{i j}=\Delta U_{i j-}$. Now in Proposition 4.5, we investigate how an SC specifies its new strategies.

Proposition 4.5. From $B_{i j}>0$, it follows that $k_{i j}\left(1-\phi_{i j}\right) \beta_{i} / \eta_{R_{j}}<3 \gamma_{i} / \beta_{i}$, and for the price changes of the rival chain, one has

(i) $\partial m_{R_{j} i}^{*} / \partial w_{M_{j-}}=\partial m_{R_{i} i}^{*} / \partial m_{R_{j-i}}=\partial w_{M_{j}}^{*} / \partial w_{M_{j-}}=\partial w_{M_{j}}^{*} / \partial m_{R_{j-} i}>0$ if $\theta_{1 i j} / \theta_{2 i j}>k_{i j}(1-$ $\left.\phi_{i j}\right) \beta_{i} / \eta_{R_{j}}, \partial S_{R_{j}}^{*} / \partial w_{M_{j-}}=\partial S_{R_{j}}^{*} / \partial m_{R_{j-i}}<0$ if $\theta_{1 i j} / \theta_{2 i j}<3 \gamma_{i} / \beta_{i}$.

Similarly, for service level changes of the rival chain, one has

(ii) $\partial m_{R_{j} i}^{*} / \partial S_{R_{j-}}=\partial w_{M_{j}}^{*} / \partial S_{R_{j-}}<0$ if $\theta_{1 i j} / \theta_{2 i j}>k_{i j}\left(1-\phi_{i j}\right) \beta_{i} / \eta_{R_{j}}$, and $\partial S_{R_{j}}^{*} / \partial S_{R_{j-}}=$ $\partial S_{R_{j}}^{*} / \partial S_{R_{j-}}>0$ if $\theta_{1 i j} / \theta_{2 i j}<3 \gamma_{i} / \beta_{i}$.

Two values $k_{i j}\left(1-\phi_{i j}\right) \beta_{i} / \eta_{R_{j}}$ and $3 \gamma_{i} / \beta_{i}$ are key thresholds which determine SC's efficient strategies against changes in the price and service level of the rival. Part (i) of Proposition 4.5 gives us the following insights. 


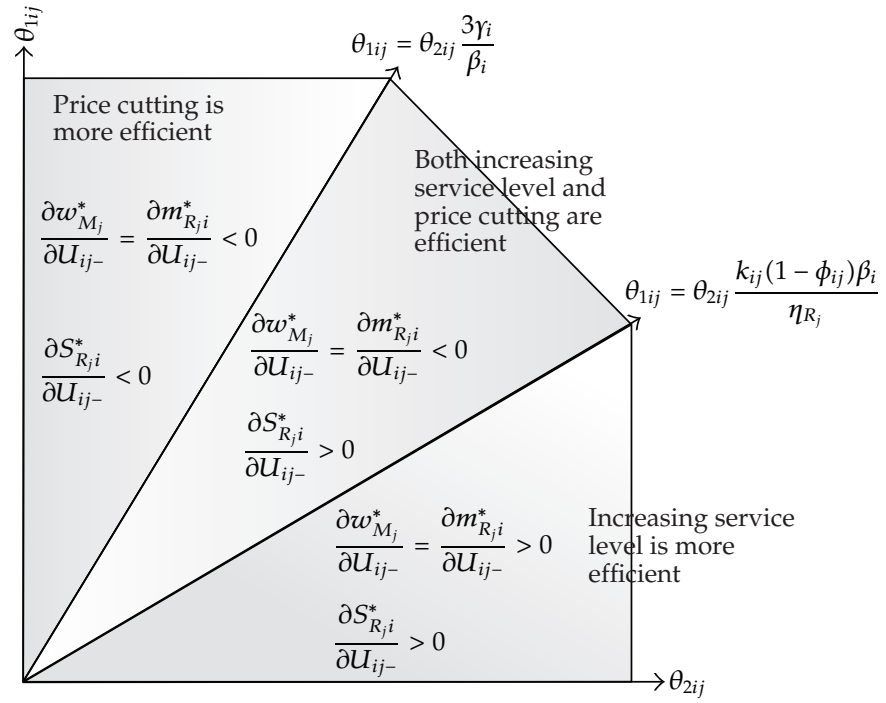

Figure 2: SC's efficient strategies for customer segment $i$ against variation in rival product utility.

(i) If $\theta_{1 i j} / \theta_{2 i j}>3 \gamma_{i} / \beta_{i}$, then declining in the product price of the rival chain $j$ - will be responded by decreasing in price and increasing in service level of SC $j$ th. However, since the customer is more responsive to price, price cutting is a more efficient strategy for rising the product's utility from the customer segment viewpoint.

(ii) If $\theta_{1 i j} / \theta_{2 i j}<k_{i j}\left(1-\phi_{i j}\right) \beta_{i} / \eta_{R_{j}}$, then the customer segment is more responsive to the service level. Therefore, if the decision makers in chain $j$ want to maintain the segment with a specific minimum probability, it is needed to compensate for a price increase with service level which is more effective.

(iii) If $k_{i j}\left(1-\phi_{i j}\right) \beta_{i} / \eta_{R_{j}}<\theta_{1 i j} / \theta_{2 i j}<3 \gamma_{i} / \beta_{i}$, then both strategies of cutting price and increasing service level are efficient.

(iv) Similarly, part (ii) states the SC's reactions to service level changes of rival chain. Cutting price and increasing service level by rival chain lead to rise in product utility. Figure 2 illustrates the efficient strategies of an SC against rising product utility by the rival.

When manufacturers and retailers in both chains consider coupled constraint (4.7), and if $\sum_{j=1}^{2}\left(1-\phi_{i j}\right) \leq 1$, then multipliers $\lambda$ corresponding to the coupled constraints must satisfy $\lambda=0$ or $\lambda>0$ (the KKT condition). Therefore, in attempting to find Nash equilibrium solution, it is sufficient to take the cases of Table 1 into account.

Therefore, Nash equilibrium solution of the competition is obtained from one of the following cases.

Case $1\left(\lambda_{i j}=0\right.$ and $\left.\lambda_{i j-}=0\right)$. Strategies of SC and rival chain are obtained by part (i) of Proposition 4.3. Here, both coupled constraints are satisfied at $\left(w_{M_{j}}^{*} m_{R_{j} i^{\prime}}^{*} S_{R_{j}}^{*}\right)$ and $\left(w_{M_{j-}}^{*}, m_{R_{j-i},}^{*} S_{R_{j-}}^{*}\right)$.

Case $2\left(\lambda_{i j}=0\right.$ and $\left.\lambda_{i j-}>0\right)$. The coupled constraint (4.7) is binding only for rival SC. Therefore, the optimal strategies of SC $j$ are achieved by part (i) of Proposition 4.3. However, 
Table 1: Four possible cases for competing chains associated with customer segment $i$.

\begin{tabular}{lll}
\hline & $\lambda_{i j}=0$ & $\lambda_{i j}>0$ \\
\hline$\lambda_{i j-}=0$ & Case 1 & Case 2 \\
$\lambda_{i j-}>0$ & Case 3 & Case 4 \\
\hline
\end{tabular}

rival chain takes the optimal strategies of the first SC into account and computes optimal strategies by part (ii) of Proposition 4.3.

Case $3\left(\lambda_{i j}>0\right.$ and $\left.\lambda_{i j-}=0\right)$. In this case, the situation is contrary to Case 2 and the coupled constraint is binding only for SC $j$.

Case $4\left(\lambda_{i j}>0\right.$ and $\left.\lambda_{i j-}>0\right)$. Here, both coupled constraints for competing SCs are binding. This rare condition takes place only if $\sum_{j=1}^{2}\left(1-\phi_{i j}\right)=1$. The optimal strategies of SC and rival are obtained by part (ii) of Proposition 4.3 .

Note that the values of $1-\phi_{i j}$ are subjective probabilities which decision makers in one SC specify it independently of rival chain. This probability is not revealed for rival. The value of $1-\phi_{i j}$ is determined based on importance and worth of customer segment $i$ and expresses that SC partners are content to sacrifice profit to win customer segment $i$ with the least probability of $1-\phi_{i j}$. The assumption $\sum_{j=1}^{2}\left(1-\phi_{i j}\right) \leq 1$ insures that a permanent equilibrium point exists in the competition, and resulting strategies $X_{i j}\left(X_{i j-}\right)$ and $X_{i j-}\left(X_{i j}\right)$ satisfy the least probability conditions for both SCs. Otherwise, SCs involve eternal competition to present the customer more favorable products, and no equilibrium exists in a one-shot competition. However, in a multiperiod competition, presenting more favorable products to the customers to increase business is the very essence of competition which brings about innovation and improvement in technology and knowledge. For instance, consider the dynamics of the microprocessor market which drives severe competition between two main suppliers, that is, AMD and Intel. The main customers of microprocessors are major original equipment manufacturers (OEMs) such as Dell, IBM, and HP which enjoy this rivalry. Throughout years of competition, Intel and AMD contest to win customers' business not just on price and service level, but on all aspects of their products including quality, performance, and reliability.

Consider an example with the following default values for parameters corresponding to customer segment $i$ :

$$
\begin{gathered}
\theta_{01}=150, \quad \theta_{1 i 1}=0.3, \quad \theta_{2 i 1}=0.7, \quad \theta_{02}=200, \quad \theta_{1 i 2}=0.25, \\
\theta_{2 i 2}=0.75, \quad \alpha_{i}=5000, \quad \gamma_{i}=10, \quad \beta_{i}=0.5 .
\end{gathered}
$$

Additionally, assume the following values for parameters of competing SCs:

$$
\begin{gathered}
\eta_{R_{1}}=\eta_{R_{2}}=0.1, \quad c_{M_{1}}=c_{M_{2}}=100, \quad \mathrm{FC}_{M_{1}}=\mathrm{FC}_{M_{2}}=20000, \\
\mathrm{FC}_{R_{1}}=\mathrm{FC}_{R_{2}}=10000, \quad P_{i 1}^{-}, P_{i 1}^{+}=5, \\
S_{R_{1} i}^{-}, S_{R_{1} i}^{+}=5, \quad P_{i 2}^{-}, P_{i 2}^{+}=5, \\
S_{R_{2} i}^{-} S_{R_{2} i}^{+}=5, \quad 1-\phi_{i 1}=0.4, \quad 1-\phi_{i 2}=0.3 .
\end{gathered}
$$


Table 2: An example for competing chains associated with customer segment $i$.

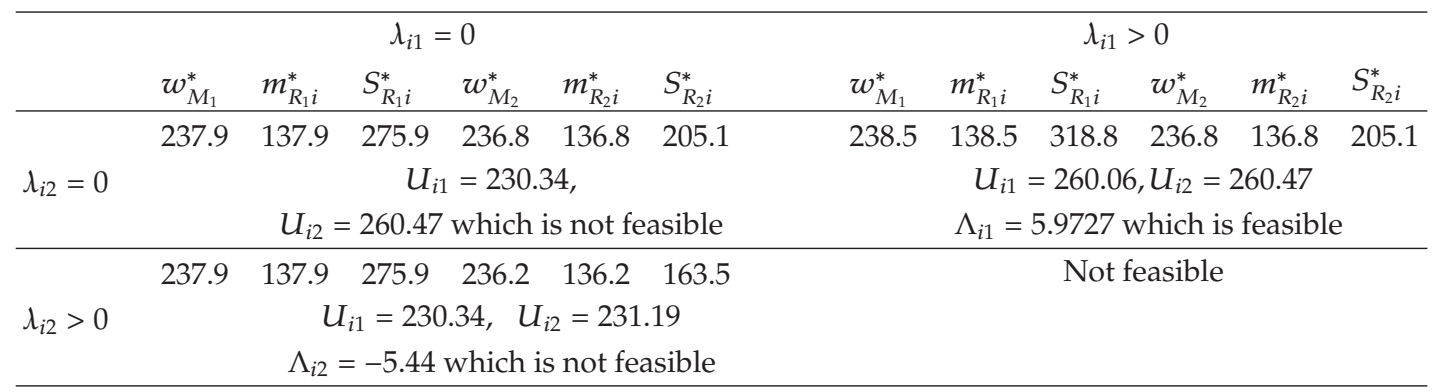

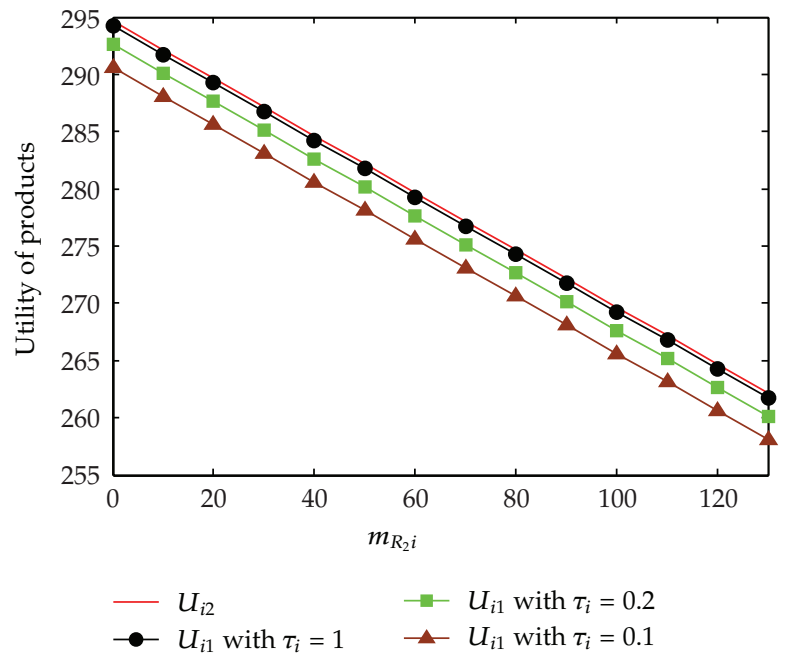

Figure 3: The products utility of SCs versus the profit margin of retailer 2 with different customer rationality parameters (with $\delta_{i 1}=1$ ).

Now for the RUM for customer segment $i$ behavior (i.e., $\tau_{i}=1$ ) and with $100 \%$ confidence level about rival strategies (i.e., $\delta_{i j}=\delta_{i j-}=1$ ), we can compute four cases in Table 1 as follows in Table 2. In Case 1, coupled constraint for SC 1 is not satisfied, thus the solution is not acceptable. Since negative value for $\lambda_{i 2}$ is not permitted, Case 3 is not feasible, as well. Case 4 is impossible because two coupled constraints cannot be binding simultaneously. Therefore, the single equilibrium solution for GNEP is obtained in Case 2 where $\lambda_{i 1}>0$ and $\lambda_{i 2}=0$. Case 2 expresses that SC 1 will win customer segment $i$ with the least acceptable probability (i.e., 0.4 ), whereas rival chain will win the customer with higher probability than 0.3 .

Table 2 represents a Nash solution for SCs competition. However, in the real-world competition, one SC may decide to cut prices or increase service level to affect the other party (or parties). For instance, assume that in the solution of Table 2, retailer in SC 2 increases his products utility by declining profit margin. Since $\theta_{1 i 1} / \theta_{2 i 1}<k_{i 1}\left(1-\phi_{i 1}\right) \beta_{i} / \eta_{R_{1}}$, it is obvious from Proposition 4.5 that rising service level is a more efficient strategy for SC $i$ against the rival retailer. Figure 3 shows that SC 1 increases its products utility along with rival's ones to hold customer segment $i$ with the least probability of 0.4 . Another important point in Figure 3 is illustrating the impact of customer rationality on SCs competition. Like QRE concept, $\tau$ can 


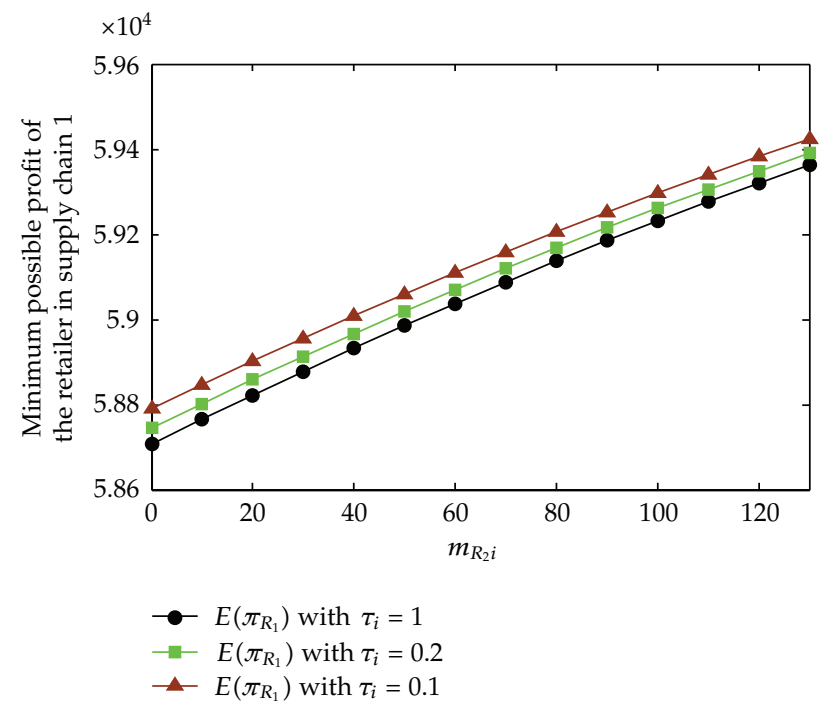

Figure 4: The minimum possible profit of retailer 1 versus the profit margin of retailer 2 with different customer rationality parameters (with $\delta_{i 1}=1$ ).

be interpreted as a rationality parameter which specifies customer responsiveness to utility of products in which $\tau_{i}=1$ leads to RUM of McFadden [7]. When $\tau_{i}=0$, the customer segment is totally indifferent about product utility and chooses the brand of products completely by chance. Herein, coupled constraints (4.7) are nonbinding for both rivals and optimal SCs strategies certainly are obtained from Case 1 of Table 1 . Adversely, $\tau_{i} \rightarrow \infty$ yields deterministic utility model. Here, in the case of certainty about rival strategies (i.e., $\delta_{i j-}^{j}=1$ or $\left.\rho_{i j-}^{j}=0\right)$, both coupled constraints are binding, and rivals require to offer product with the same utility to the customer; therefore, the optimal strategies of SCs are achieved from Case 4 of Table 1.

We can conclude that, when a customer segment is highly responsive to utility, each SC needs to present products with utility close to rival's ones which brings about more severe competition. Therefore, customer purchasing behavior dictates severity of competition in the market which is consistent with the real-world competition.

Figures 4 and 5 illustrate profit variation of the retailer and manufacturer in SC 1 against price cutting strategy of retailer 2. Since rising service level investment and product price are reactive strategies of SC 1 , profit of retailer 1 declines due to higher service level. However, increasing product price leads to rise in profit of manufacturer 1.

Figure 6 shows the wholesale and retail-sale prices, and service level investment in the case of existence of vagueness about rival chain strategies. In Figure 5, lower confidence level $\delta_{i 1}$ brings about lesser price and service level investment. From Figure 7, it can be concluded that lower $\delta_{i 1}$ makes offering products with lesser utility for the customer. Therefore, by decreasing $\delta_{i 1}$, there is more possibility to lose the customer. Figure 8 demonstrates variation in the possible profit of the retailer and manufacturer in SC 1 against different confidence level. When $\delta_{i 1}=0$, the confidence level to win the customer segment approaches zero; thus, fixed cost and service level cost cause a negative profit for the retailer and manufacturer. 


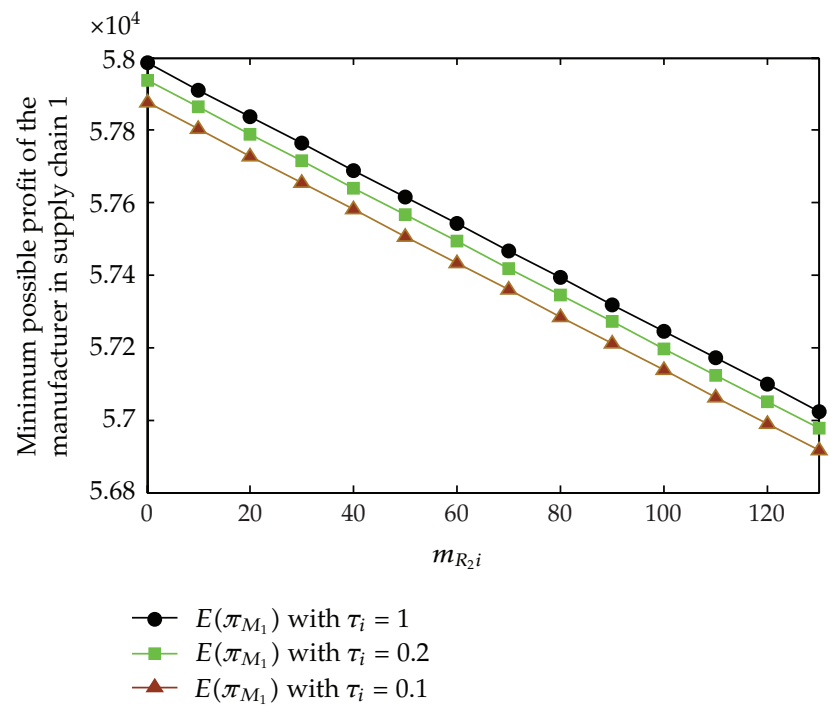

Figure 5: The minimum possible profit of manufacturer 1 versus the profit margin of retailer 2 with different customer rationality parameters (with $\delta_{i 1}=1$ ).

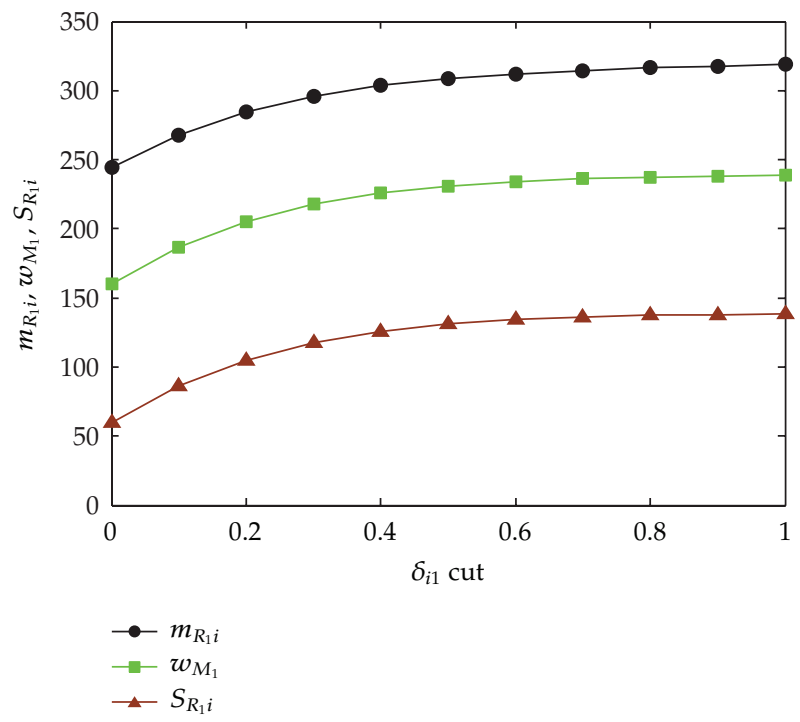

Figure 6: Strategies of SC 1 versus the confidence level of rival fuzzy strategy (with $\tau_{i}=1$ ).

\subsection{Extension of Retailers and Manufacturers Problems in a Market}

Consider a product market $M$ which consists of $n$ customer segments with different demands and utility functions. In the real-world competitions, SCs often present different prices and service levels to the customer segments. Each segment selects one product type based on RUM. In this case, the SC competition model can be extended for this market. The possible profit of the manufacturer in a market is obtained from the aggregate possible profit 


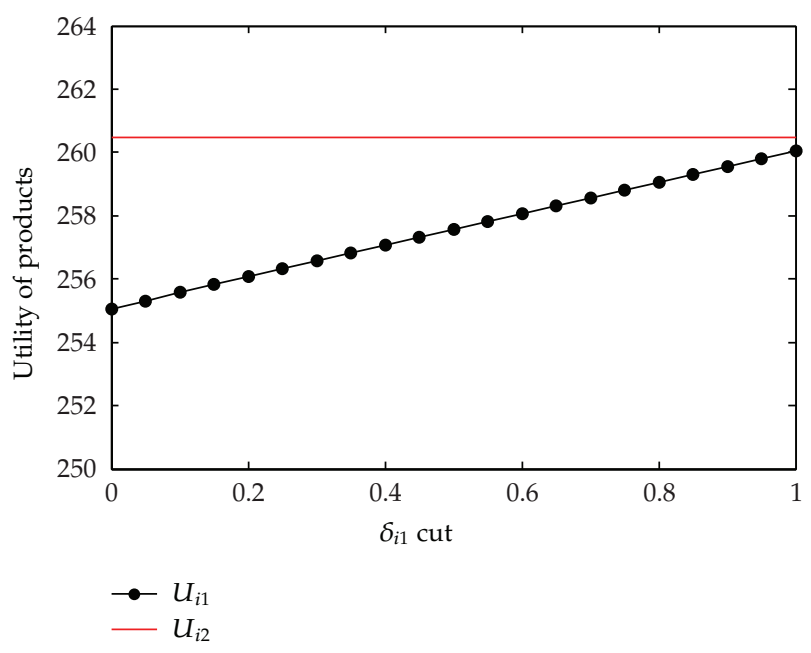

Figure 7: The products utility of SCs versus the confidence level of rival fuzzy strategy (with $\tau_{i}=1$ ).

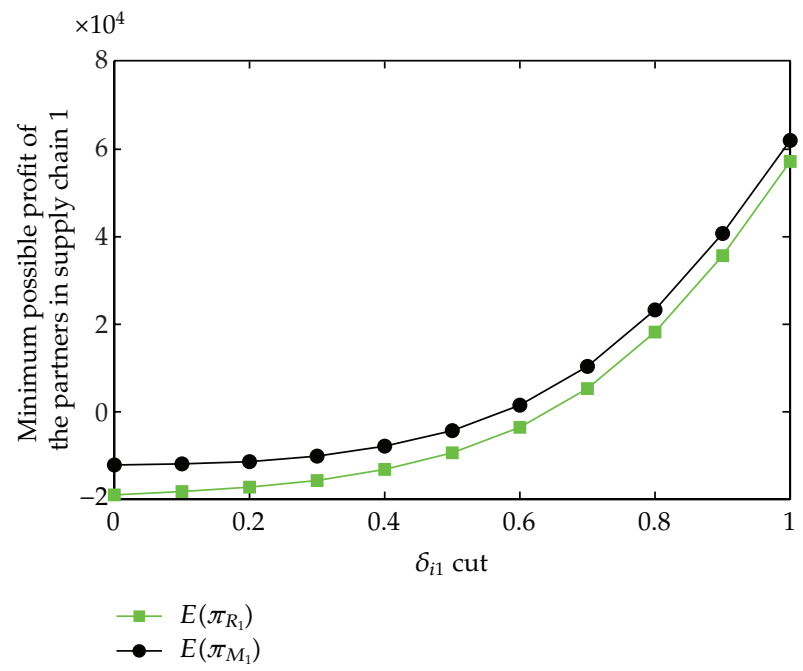

Figure 8: The minimum possible profit of partners in SC 1 versus the confidence level of rival fuzzy strategy (with $\tau_{i}=1$ ).

from customer segments. Therefore, the problem of the manufacturer in SC $j$ is defined as follows:

$$
\max _{w_{M_{j}}} E\left(\pi_{M_{j}}\right)=\sum_{i \in M} k_{i j}\left(1-\phi_{i j}\right)\left(w_{M_{j}}-c_{M_{j}}\right)\left[\alpha_{i}-\gamma_{i}\left(w_{M_{j}}+m_{R_{j} i}\right)+\beta_{i} S_{R_{j} i}\right]-\mathrm{FC}_{M_{j}},
$$

subject to

$$
\theta_{0 j}-\theta_{0 j-}-\theta_{1 i j}\left(w_{M_{j}}+m_{R_{j} i}\right)+\theta_{1 i j-} P_{i j-}+\theta_{2 i j} S_{i j}-\theta_{2 i j-} S_{2 i j-} \geq Q_{i j}, \quad \forall i \in M
$$


Additionally, the mathematical formulation of the retailer in SC $j$ is as follows:

$$
\max _{m_{R_{j} i}, S_{R_{j} i}} E\left(\pi_{R_{j}}\right)=\sum_{i \in M}\left[k_{i j}\left(1-\phi_{i j}\right) m_{R_{j} i}\left[\alpha_{i}-\gamma_{i}\left(w_{M_{j}}+m_{R_{j} i}\right)+\beta_{i} S_{R_{j} i}\right]-\frac{1}{2} \eta_{R_{j}} S_{R_{j} i}{ }^{2}\right]-\mathrm{FC}_{M_{j}},
$$

subject to constraint (4.18), where $k_{i j}=\left[1-\phi_{i j}+\phi_{i j} \exp \left(\rho_{i j-}^{j} \tau_{i}\left(1-\delta_{i j-}^{j}\right)\right)\right]^{-1}$ and $Q_{i j}=\left(1 / \tau_{i}\right)$ $\ln \left[\left(1-\phi_{i j}\right) / \phi_{i j}\right]-\left(1-\delta_{i j-}^{j}\right) \rho_{i j-}^{j}$.

Objective functions (4.17) and (4.19) indicate possible manufacturer and retailer from purchasing products to customer segments set $n$, respectively. Coupled constraint (4.18) assures that the least probability of winning each customer segment is not less than the minimum acceptable probability. Since the coupled constraints for both chains can be binding or nonbinding with regard to each customer segment, $4^{n}$ cases can occurr. Proposition 4.5 states that a single Nash equilibrium solution of the model will exist.

Proposition 4.6. When $\sum_{j=1}^{2}\left(1-\phi_{i j}\right) \leq 1$ and $B_{i j}^{\prime}>0$ hold for each customer segment $i$ and SC $j, a$ single Nash equilibrium for SCs strategies is found from $4^{n}$ cases of KKT condition.

Parametric solutions of KKT condition for even two customer segments are too large to summarize in the paper; however, the numerical examples can easily be solved by numerical solvers. For instance, assume that two customer segments exist in the previous numerical example with the following parameters:

$$
\begin{gathered}
\theta_{01}=150, \quad \theta_{02}=200, \quad \theta_{111}=0.3, \quad \theta_{211}=0.7, \quad \theta_{112}=0.25, \quad \theta_{212}=0.75, \\
\theta_{121}=0.2, \quad \theta_{221}=0.8, \quad \theta_{122}=0.3, \quad \theta_{222}=0.7, \quad \alpha_{1}=5000, \quad \alpha_{2}=6000, \\
\gamma_{1}, \gamma_{2}=10, \quad \beta_{1}=0.5, \quad \beta_{2}=0.8 .
\end{gathered}
$$

Additionally, assume the following parameters for competing chains:

$$
\begin{gathered}
P_{i j}^{-}, P_{i j}^{+}, S_{R_{j} i}^{-}, S_{R_{j} i}^{+}=5, \quad \forall i, j \in\{1,2\}, \\
1-\phi_{11}=0.4, \quad 1-\phi_{12}=0.3, \quad 1-\phi_{21}=0.2, \quad 1-\phi_{22}=0.25 .
\end{gathered}
$$

Therefore, in the case of $\tau_{i}=1$ and $\delta_{i j-}^{j}=1$ for all $i, j \in\{1,2\}$, we have $Q_{11}=-4.055$, $Q_{12}=-8.473, Q_{21}=-1.386$, and $Q_{22}=-1.099$. Since SCs compete for two customer segments, $4^{2}$ cases in Table 2 should be investigated. Based on KKT conditions, the feasible and optimal case is needed to hold $\lambda_{i j} \geq 0$ for all $i, j \in\{1,2\}, 4.055 \leq U_{11}-U_{12} \leq 8.473$, and $1.386 \leq$ $U_{21}-U_{22} \leq 1.099$.

In the solutions of Table 3 , the single feasible and optimal solution is related to $\lambda_{11}=$ $\lambda_{21}=0, \lambda_{12}=11.22$, and $\lambda_{22}=14.00$. Therefore, in the Nash equilibrium, coupled constraint for customer segment 1 and SC 2 and coupled constraint for customer 2 and SC 1 are binding as well. Consequently, SC 2 will win customer segment 1 with the least probability of 0.3 ; however, SC 1 will attract the customer segment 1 with probability more than 0.4 . Similarly, SC 1 (and 2) will win customer segment 2 with probability of 0.2 (more than 0.25 ). 


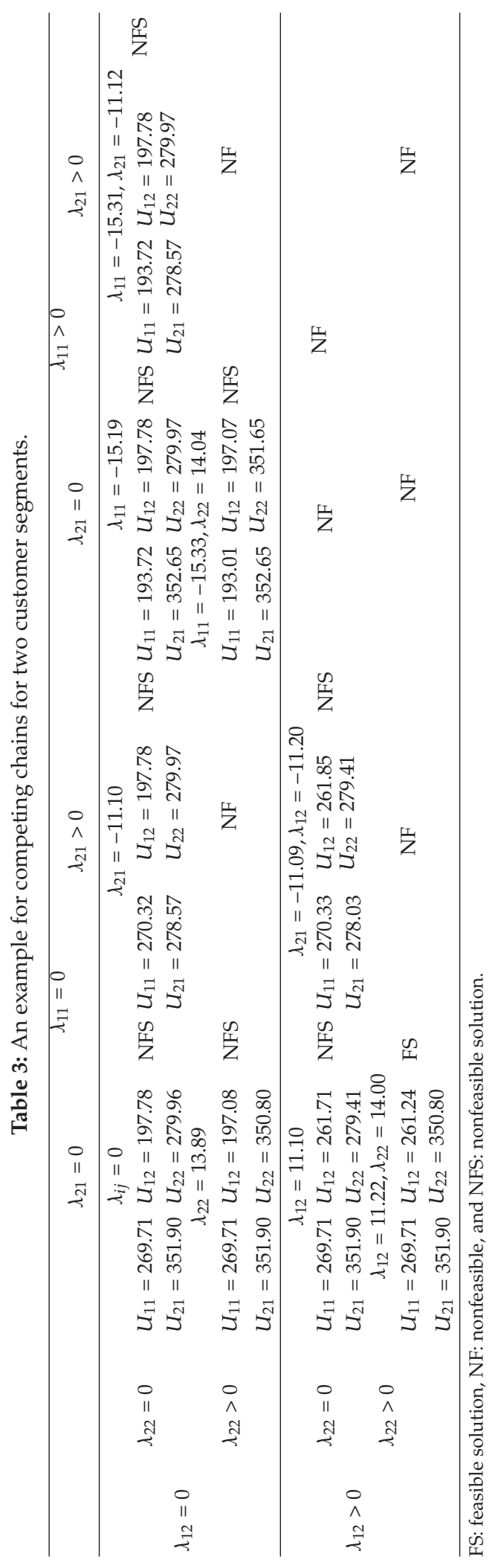


Note that confidence levels about rival strategies can be varied or equal for different customer segments. Moreover, the degree of customer responsiveness to utility (rationality) will affect the degree of severity of the competition between chains for that customer.

\section{Conclusion}

In this paper, we develop a generalized Nash equilibrium model for the competition between two SCs where their customers are free to choose. We examine the situation where SC's decision makers consider minimum probabilities for attracting the customers based on customers worth for the SC. Using coupled constraints concept in GNEPs, these probabilities are involved in competition model formulations. Finally, the equilibrium strategies for consequent GNEPs are obtained from exploring possible cases of KKT condition. We show that SCs competition is affected by customer purchasing behaviors due to two reasons. In the first place, higher rational customers dictate more severe competition between chains. Secondly, efficient response of an SC to the variation in rival strategies depends on the sensitivity of the customer segment to price and service level. Moreover, we investigate the impacts of vagueness regarding rival strategies on SC decisions. We find that decision makers with different confidence levels about rival strategies may achieve different retail price and service level. The less the confidence level about the rival strategies, the less the actual probability of wining customer will be.

\section{Appendix}

Proof of Lemma 4.1. Constraint (4.2) can be transformed into

$$
\phi_{i j} \exp \left(\tau_{i}\left(\theta_{0 j}-\theta_{1 i j} P_{i j}+\theta_{2 i j} S_{R_{j} i}\right)\right) \geq\left(1-\phi_{i j}\right) \exp \left(\tau_{i}\left(\theta_{0 j-}-\theta_{1 i j-} \widetilde{P}_{i j-}+\theta_{2 i j-} \widetilde{S}_{R_{j-} i}\right)\right)
$$

Natural logarithm of inequation (A.1) leads to

$$
\left(\theta_{0 j}-\theta_{1 i j} P_{i j}+\theta_{2 i j} S_{R_{j} i}\right)-\left(\theta_{0 j-}-\theta_{1 i j-} \widetilde{P}_{i j-}+\theta_{2 i j-} \widetilde{S}_{R_{j-} i}\right) \geq \frac{1}{\tau_{i}} \ln \left(\frac{1-\phi_{i j}}{\phi_{i j}}\right) .
$$

Now let $\mu_{\tilde{P}_{i j-}}\left(P_{i j-}\right)$ and $\mu_{\widetilde{S}_{R_{j-i}}}(y)$ be the membership functions of $\widetilde{P}_{i j-}$ and $\widetilde{S}_{R_{j-i}}$ as follows:

$$
\mu_{\tilde{P}_{i j-}}\left(P_{i j-}\right)= \begin{cases}\max \left\{0,1-\frac{P_{i j-}-y}{P_{i j-}^{-}}\right\} & \text {if } y \leq P_{i j-}, \\ \max \left\{0,1-\frac{y-P_{i j-}}{P_{i j-}^{+}}\right\} & \text {if } y>P_{i j-},\end{cases}
$$




$$
\mu_{\widetilde{S}_{R_{j-i}}}(y)= \begin{cases}\max \left\{0,1-\frac{S_{R_{j-i}-}-y}{S_{R_{j-i}}^{-}}\right\} & \text {if } y \leq S_{R_{j-i},}, \\ \max \left\{0,1-\frac{y-S_{R_{j-i} i}}{S_{R_{j-i}}^{+}}\right\} & \text {if } y>S_{R_{j-i},}\end{cases}
$$

and let $Y_{\delta_{i j-}^{j}}=\left\{y \mid \mu_{\tilde{P}_{i j-}}\left(P_{i j-}\right) \geq \delta_{i j-}^{j}, \mu_{\widetilde{S}_{R_{j-}}}(y) \geq \delta_{i j-^{\prime}}^{j}, y \geq 0\right\}$ for each $\delta_{i j-}^{j} \in[0,1]$ be the $\delta_{i j-}^{j}$ level cut for the price and service level membership functions. By substituting $\delta_{i j-}^{j}$ level cut of membership functions (A.3) into constraint (A.2) [62], we have

$$
\theta_{0 j}-\theta_{0 j-}-\theta_{1 i j} P_{i j}+\theta_{1 i j-} P_{i j-}+\theta_{2 i j} S_{i j}-\theta_{2 i j-} S_{R_{j-i}} \geq \ln \left(\frac{1-\phi_{i j}}{\phi_{i j}}\right)^{1 / \tau_{i}}-\left(1-\delta_{i j-}^{j}\right)\left(\theta_{i j 1} P_{i j-}^{+}+\theta_{i j 2} S_{R_{j-i}}^{-}\right) .
$$

Proof of Lemma 4.2. Regarding the uncertainty about competitor strategies, the term (1 $\left.\delta_{i j-}^{j}\right) \rho_{i j}$ appeared in the right hand side of constraint (4.4). This term causes a change in probability of attracting the customer. Let $1-\phi_{i j}^{\prime}$ be the new minimum probability of attracting customer segment $i$. This probability is obtained from the following equation:

$$
\ln \left(\frac{1-\phi_{i j}}{\phi_{i j}}\right)^{1 / \tau_{i}}-\left(1-\delta_{i j-}^{j}\right) \rho_{i j-}^{j}=\ln \left(\frac{1-\phi_{i j}^{\prime}}{\phi_{i j}^{\prime}}\right)^{1 / \tau_{i}}
$$

By solving (A.5) for $\phi_{i j}^{\prime}$, we have

$$
1-\phi_{i j}^{\prime}=\left(1-\phi_{i j}\right) \frac{1}{1-\phi_{i j}+\phi_{i j} \exp \left(\rho_{i j-}^{j} \tau_{i}\left(1-\delta_{i j-}^{j}\right)\right)}=\left(1-\phi_{i j}\right) k_{i j}
$$

Proof of Proposition 4.3. Consider KKT condition for manufacturer objective function (4.6) and retailer objective function (4.9) along with constraint (4.7). Since $\partial^{2} E\left(\pi_{M_{j}}\right) / \partial w_{M_{j}}^{2}=-2 \gamma_{i} \leq 0$, objective function (4.6) corresponding to manufacturer $j$ is concave on $w_{M_{j}}$. On the other hand, Hessian matrix of retailer objective function (4.9) is

$$
\mathbf{H}_{R_{j}}=\left[\begin{array}{cc}
-2 k_{i j}\left(1-\phi_{i j}\right) \gamma_{i} & k_{i j}\left(1-\phi_{i j}\right) \beta_{i} \\
k_{i j}\left(1-\phi_{i j}\right) \beta_{i} & -\eta_{R_{j}}
\end{array}\right]
$$

$E\left(\pi_{R_{j}}\right)$ is concave function on $\left(m_{R_{j}}, s_{R_{j}}\right)$ if and only if the Hessian matrix is negatively definite. Due to $0 \leq k_{i j}\left(1-\phi_{i j}\right) \leq 1, \gamma_{i}, \eta_{R_{j}} \geq 0$, and $B_{i j}^{\prime}>0$, retailer objective function (4.9) is concave [54]. Moreover, since the left side of coupled constraint (4.7) is a linear and continuous function and all gradients at point $X_{i j}=\left(w_{M_{j}}, m_{R_{j}}, s_{R_{j}}\right)$ exist, the constraint qualification of KKT condition is satisfied at this point. If $X_{i j}^{*}=\left(w_{M_{j}}^{*}, m_{R_{j}}^{*}{ }^{\prime} s_{R_{j}}^{*}\right)$ is an optimal 
strategy of the manufacturer and retailer in SC $j$ corresponding to customer segment $i$, then $X_{i j}^{*}$ must satisfy constraint (4.7), and there must exist multiplier $\lambda_{i j}$ satisfying

$$
\begin{gathered}
k_{i j}\left(1-\phi_{i j}\right)\left[\alpha_{i}-\gamma_{i}\left(w_{M_{j}}^{*}+m_{R_{j} i}^{*}\right)+\beta_{i} S_{R_{j}}^{*}\right]-k_{i j}\left(1-\phi_{i j}\right) \gamma_{i}\left(w_{M_{j}}^{*}-c_{M_{j}}\right)-\lambda_{i j} \theta_{1 i j}=0, \\
k_{i j}\left(1-\phi_{i j}\right)\left[\alpha_{i}-\gamma_{i}\left(w_{M_{j}}^{*}+m_{R_{j} i}^{*}\right)+\beta_{i} S_{R_{j}}^{*}\right]-k_{i j}\left(1-\phi_{i j}\right) \gamma_{i} m_{R_{j} i}^{*}-\lambda_{i j} \theta_{1 i j}=0, \\
k_{i j}\left(1-\phi_{i j}\right) \beta_{i} m_{R_{j} i}^{*}-\eta_{R_{j}} S_{R_{j}}^{*}+\lambda_{i j} \theta_{2 i j}=0, \\
\lambda_{i j}\left[\theta_{0 j}-\theta_{0 j-}-\theta_{1 i j}\left(w_{M_{j}}^{*}+m_{R_{j} i}^{*}\right)+\theta_{1 i j-} P_{i j-}+\theta_{2 i j} S_{j}^{*}-\theta_{2 i j-} S_{i j-}-Q_{i j}\right]=0, \\
\lambda_{i j} \geq 0 .
\end{gathered}
$$

The optimal strategies $\left(w_{M_{j}}^{*} m_{R_{j} i^{\prime}}^{*} s_{R_{j}}^{*}\right)$ are found by solving simultaneously system of (A.8) which are equal to optimal values in the proposition. Thus, the Proposition 4.3 follows.

Proof of Proposition 4.4. Proof of the proposition is straightforward from the first-order deviations of optimal strategies in Proposition 4.3.

Proof of Proposition 4.5. In Proposition 4.4, the denominators of all fractions are positive because

$$
2 \theta_{1 i j} E_{i j}-\theta_{2 i j} k_{i j}\left(1-\phi_{i j}\right) F_{i j}=3 \theta_{2 i j}^{2} \gamma_{i} k_{i j}\left(1-\phi_{i j}\right)+2 \theta_{1 i j}^{2} \eta_{R_{j}}-3 \theta_{1 i j} \theta_{2 i j} k_{i j}\left(1-\phi_{i j}\right) \beta_{i},
$$

and from $B_{i j}=3 \gamma_{i} \eta_{R_{j}}-k_{i j}\left(1-\phi_{i j}\right) \beta_{i}{ }^{2}>0$ and $0 \leq k_{i j}\left(1-\phi_{i j}\right) \leq 1$, we know that $2 \sqrt{6 \gamma_{i} \eta_{R_{j}}}>$ $3 k_{i j}\left(1-\phi_{i j}\right) \beta_{i}$; therefore, it follows that

$$
\begin{aligned}
& 3 \theta_{2 i j}^{2} \gamma_{i} k_{i j}\left(1-\phi_{i j}\right)+2 \theta_{1 i j}^{2} \eta_{R_{j}}-3 \theta_{1 i j} \theta_{2 i j} k_{i j}\left(1-\phi_{i j}\right) \beta_{i} \\
& \geq 3 \theta_{2 i j}^{2} \gamma_{i} k_{i j}\left(1-\phi_{i j}\right)+2 \theta_{1 i j}^{2} \eta_{R_{j}}-2 \theta_{1 i j} \theta_{2 i j} \sqrt{6 k_{i j}\left(1-\phi_{i j}\right) \gamma_{i} \eta_{R_{j}}} \\
& =\left(\theta_{2 i j} \sqrt{3 \gamma_{i} k_{i j}\left(1-\phi_{i j}\right)}-\theta_{1 i j} \sqrt{2 \eta_{R_{j}}}\right)^{2} \geq 0 .
\end{aligned}
$$

Since $2 \theta_{1 i j} E_{i j}-\theta_{2 i j} k_{i j}\left(1-\phi_{i j}\right) F_{i j}>0$, all derivatives in Proposition 4.4 have the same sign as their numerators. Thus, from $E_{i j}>0 \Leftrightarrow \theta_{1 i j} / \theta_{2 i j}>k_{i j}\left(1-\phi_{i j}\right) \beta_{i} / \eta_{R_{j}}$ and $F_{i j}>0 \Leftrightarrow \theta_{1 i j} / \theta_{2 i j}>$ $3 \gamma_{i} / \beta_{i}$, all statements in Proposition 4.5 follow. 
Proof of Proposition 4.6. First, we show that $E\left(\pi_{R_{j}}\right)$ is a concave function on $m_{R_{j} i}$ and $S_{R_{j} i}$ for all $i \in M$. The Hessian matrix of $E\left(\pi_{R_{j}}\right)$ is

$$
H=\left[\begin{array}{cccccccc}
-2 \Omega_{11} \gamma_{1} & 0 & \cdots & 0 & \Omega_{11} \beta_{1} & 0 & \cdots & 0 \\
0 & -2 \Omega_{21} \gamma_{2} & \cdots & 0 & 0 & \Omega_{21} \beta_{2} & \cdots & 0 \\
\vdots & \vdots & \vdots & \vdots & \vdots & \vdots & \vdots & \vdots \\
0 & 0 & \cdots & -2 \Omega_{n 1} \gamma_{n} & 0 & 0 & \cdots & \Omega_{n 1} \beta_{n} \\
\Omega_{11} \beta_{1} & 0 & \cdots & 0 & -\eta_{R_{1}} & 0 & \cdots & 0 \\
0 & \Omega_{21} \beta_{2} & \cdots & 0 & 0 & -\eta_{R_{2}} & \cdots & 0 \\
\vdots & \vdots & \vdots & \vdots & \vdots & \vdots & \vdots & \vdots \\
0 & 0 & \cdots & \Omega_{n 1} \beta_{n} & 0 & 0 & \cdots & -\eta_{R_{n}}
\end{array}\right]
$$

where $\Omega_{i 1}$ denotes to $k_{i 1}\left(1-\phi_{i 1}\right)$. By performing elementary Gauss-Jordan operation using $n$ first rows of $H$, the following upper triangular matrix is obtained:

$$
H=\left[\begin{array}{cccccccc}
-2 \Omega_{11} \gamma_{1} & 0 & \cdots & 0 & \Omega_{11} \beta_{1} & 0 & \cdots & 0 \\
0 & -2 \Omega_{21} \gamma_{2} & \cdots & 0 & 0 & \Omega_{21} \beta_{2} & \cdots & 0 \\
\vdots & \vdots & \vdots & \vdots & \vdots & \vdots & \vdots & \vdots \\
0 & 0 & \cdots & -2 \Omega_{n 1} \gamma_{n} & 0 & 0 & \cdots & \Omega_{n 1} \beta_{n} \\
0 & 0 & \cdots & 0 & \frac{\Omega_{11} \beta_{1}^{2}}{2 \gamma_{1}}-\eta_{R_{1}} & 0 & \cdots & 0 \\
0 & 0 & \cdots & 0 & 0 & \frac{\Omega_{21} \beta_{2}{ }^{2}}{2 \gamma_{2}}-\eta_{R_{1}} \cdots & 0 \\
\vdots & \vdots & \vdots & \vdots & \vdots & \vdots & \vdots & \vdots \\
0 & 0 & \cdots & 0 & 0 & 0 & \cdots & \frac{\Omega_{n 1} \beta_{n}{ }^{2}}{2 \gamma_{n}}-\eta_{R_{n}}
\end{array}\right] .
$$

From $B_{i j}^{\prime}>0$ and $0 \leq k_{i j}\left(1-\phi_{i j}\right) \leq 1$, it follows that all diagonal elements of the matrix are negative; thus, Hessian matrix is negative definite and $E\left(\pi_{R_{j}}\right)$ is a concave function on $\left(m_{R_{j} i}, S_{R_{j} i}\right)$ for all $i \in M$. [54]. Moreover, from $\partial^{2} E\left(\pi_{M_{j}}\right) / \partial w_{M_{j}}{ }^{2}=-\sum_{i \in M} k_{i j}\left(1-\phi_{i j}\right) \gamma_{i}<$ 0 , it follows that $E\left(\pi_{M_{j}}\right)$ is concave on $w_{M_{j}}$. Retailers in both chains determine strategies $\left(m_{R_{j} i}^{*}, S_{R_{j} i}^{*}\right)$ and $\left(m_{R_{j-i}}^{*}, S_{R_{j-i}}^{*}\right)$ regarding customer segment $i$ independently of others segment. Therefore, in KKT conditions of the GNEP, one case of Table 1 will give equilibrium solution for each customer segment. 


\section{Acknowledgment}

The authors would like to appreciate the anonymous referee who revised our paper for his/her constructive suggestions.

\section{References}

[1] K. Kogan and C. S. Tapiero, Supply Chain Games: Operations Management and Risk Valuation, vol. 113 of International Series in Operations Research \& Management Science, Springer, New York, NY, USA, 2007.

[2] J. B. Rosen, "Existence and uniqueness of equilibrium points for concave N-person games," Econometrica, vol. 33, pp. 520-534, 1965.

[3] F. Facchinei, A. Fischer, and V. Piccialli, "On generalized Nash games and variational inequalities," Operations Research Letters, vol. 35, no. 2, pp. 159-164, 2007.

[4] B. Wierenga, Ed., Handbook of Marketing Decision Models, vol. 121 of International Series in Operations Research \& Management Science, Springer, New York, NY, USA, 2008.

[5] P. Koltler and K. L. Keller, Marketing Management, Pearson-Prentice Hall, NJ, USA, 12th edition, 2006.

[6] J. B. Ayers, Ed., Handbook of Supply Chain Management, APICS Series on Resource Management, St. Lucie Press, 2001.

[7] D. McFadden, Conditional Logit Analysis of Qualitative Choice Behavior, Frontier in Econometrics, Academic Press, New York, NY, USA, 1974.

[8] R. D. McKelvey and T. R. Palfrey, "Quantal response equilibria for normal form games," Games and Economic Behavior, vol. 10, no. 1, pp. 6-38, 1995.

[9] R. D. McKelvey and T. R. Palfrey, "Quantal response equilibria for extensive form games," Experimental Economics, vol. 1, no. 1, pp. 9-41, 1998.

[10] G. P. Cachon and S. Netessine, "Game theory in supply chain analysis," in Handbook of Quantitative Supply Chain Analysis-Modeling in the E-business, D. Simchi-Levi, S. D. Wu, S. D. Wu, and Z. Shen, Eds., Kluwer Academic Publishers, Boston, Mass, USA, 2003.

[11] M. Leng and M. Parlar, "Game theoretic applications in supply chain management: a review," Information Systems and Operations Research, vol. 43, no. 3, pp. 187-220, 2005.

[12] G. Allon and A. Federgruen, "Competition in service industries," Operations Research, vol. 55, no. 1, pp. 37-55, 2007.

[13] G. Aydin and E. L. Porteus, "Joint inventory and pricing decisions for an assortment," Operations Research, vol. 56, no. 5, pp. 1247-1255, 2008.

[14] F. Bernstein and A. Federgruen, "A general equilibrium model for industries with price and service competition," Operations Research, vol. 52, no. 6, pp. 868-886, 2004.

[15] F. Bernstein and A. Federgruen, "Coordination mechanisms for supply chains under price and service competition," Manufacturing and Service Operations Management, vol. 9, no. 3, pp. 242-262, 2007.

[16] G. Gallego, W. T. Huh, W. Kang, and R. Phillips, "Price competition with the attraction demand model: existence of unique equilibrium and its stability," Manufacturing and Service Operations Management, vol. 8, no. 4, pp. 359-375, 2006.

[17] V. Gaur and Y. H. Park, "Asymmetric consumer learning and inventory competition," Management Science, vol. 53, no. 2, pp. 227-240, 2007.

[18] W. J. Hopp and X. Xu, "A static approximation for dynamic demand substitution with applications in a competitive market," Operations Research, vol. 56, no. 3, pp. 630-645, 2008.

[19] A. A. Levis and L. G. Papageorgiou, "Active demand management for substitute products through price optimisation," OR Spectrum, vol. 29, no. 4, pp. 551-577, 2007.

[20] Y. Wang, "Joint pricing-production decisions in supply chains of complementary products with uncertain demand," Operations Research, vol. 54, no. 6, pp. 1110-1127, 2006.

[21] C. Wu, N. C. Petruzzi, and D. Chhajed, "Vertical integration with price-setting competitive newsvendors," Decision Sciences, vol. 38, no. 4, pp. 581-610, 2007.

[22] T. Xiao and D. Yang, "Risk sharing and information revelation mechanism of a one-manufacturer and one-retailer supply chain facing an integrated competitor," European Journal of Operational Research, vol. 196, no. 3, pp. 1076-1085, 2009.

[23] T. Xiao and D. Yang, "Price and service competition of supply chains with risk-averse retailers under demand uncertainty," International Journal of Production Economics, vol. 114, no. 1, pp. 187-200, 2008. 
[24] A. Hafezalkotob, A. Makui, and S. J. Sadjadi, "Strategic and tactical design of competing decentralized supply chain networks with risk-averse participants for markets with uncertain demand," Mathematical Problems in Engineering, vol. 2011, Article ID 325610, 27 pages, 2011.

[25] A. Hafezalkotob and A. Makui, "Modeling risk of losing a customer in a two-echelon supply chain facing an integrated competitor: a game theory approach," International Journal of Engineering. In press.

[26] A. A. Tsay and N. Agrawal, "Channel dynamics under price and service competition," Manufacturing and Service Operations Management, vol. 2, no. 4, pp. 372-391, 2000.

[27] M. Larbani, "Non cooperative fuzzy games in normal form: a survey," Fuzzy Sets and Systems, vol. 160, no. 22, pp. 3184-3210, 2009.

[28] D. Garagic and J. B. Cruz, "An approach to fuzzy noncooperative Nash games," Journal of Optimization Theory and Applications, vol. 118, no. 3, pp. 475-491, 2003.

[29] L. A. Zadeh, "Fuzzy sets," Information and Control, vol. 8, no. 3, pp. 338-353, 1965.

[30] E. H. Mamdani, "Application of fuzzy algorithms for control of simple dynamic plant," Procceding of the IEEE, vol. 121, no. 12, pp. 1585-1588, 1974.

[31] J. P. Aubin, "Coeur et valeur des jeux floues," Comptes Rendus deL' Académie des Sciences de Paris, vol. 279, pp. 891-894, 1974.

[32] D. Butnariu, "Fuzzy games: a description of the concept," Fuzzy Sets and Systems, vol. 1, no. 3, pp. 181-192, 1978.

[33] D. Butnariu, "An existence theorem for possible solutions of a two person fuzzy game," Bulletin Mathematique de la Societe des Sciences de la Republique Socialistede Roumanie Tome, vol. 23, no. 71, pp. 29-35, 1979.

[34] D. Butnariu, "A fixed point theorem and its application to fuzzy games," Revue Roumaine des Mathematiques Pures et Appliquees, vol. 24, no. 10, pp. 1425-1432, 1979.

[35] D. Butnariu, "Solution concept for n-Person games," in Advances in Fuzzy Set Theory and Application, M. M. Gupta, R. K. Ragade, and R. R. Yager, Eds., North Holand, 1979.

[36] A. Billot, "A contribution to a mathematical theory of fuzzy games. Fuzzy economics and spatial analysis," in Librairie de l'Universite de Dijon, C. Ponsard and B. Fustier, Eds., pp. 47-56, 1986.

[37] J. J. Buckley, "Multiple goal non-cooperative conflicts under uncertainty: a fuzzy set approach," Fuzzy Sets and Systems, vol. 13, no. 2, pp. 107-124, 1984.

[38] L. Campos, "Fuzzy linear programming models to solve fuzzy matrix games," Fuzzy Sets and Systems, vol. 32, no. 3, pp. 275-289, 1989.

[39] I. Nishizaki and M. Sakawa, "Equilibrium solutions in multiobjective bimatrix games with fuzzy payoffs and fuzzy goals," Fuzzy Sets and Systems, vol. 111, no. 1, pp. 99-116, 2000.

[40] F. Kacher and M. Larbani, "Existence of equilibrium solution for a non-cooperative game with fuzzy goals and parameters," Fuzzy Sets and Systems, vol. 159, no. 2, pp. 164-176, 2008.

[41] Q. Song and A. Kandel, "A fuzzy approach to strategic games," IEEE Transactions on Fuzzy Systems, vol. 7, no. 6, pp. 634-642, 1999.

[42] C. Francesco and G. D. Gravio, "Multistage bilateral bargaining model with incomplete informationA fuzzy approach," International Journal of Production Economics, vol. 117, no. 2, pp. 235-243, 2009.

[43] N. F. Matsatsinis and A. P. Samaras, "Brand choice model selection based on consumers' multicriteria preferences and experts' knowledge," Computers and Operations Research, vol. 27, no. 7-8, pp. 689-707, 2000.

[44] S. Basuroy and D. Nguyen, "Multinomial logit market share models: equilibrium characteristics and strategic implications," Management Science, vol. 44, no. 10, pp. 1396-1408, 1998.

[45] L. G. Cooper, "Market-share models," in Handbooks of Operations Research and Management Science, J. Eliashberg and G. L. Lillien, Eds., Elsevier Science, Amsterdam, The Netherlands, 1993.

[46] P. B. Seetharaman, "Probabilistic versus random-utility models of state dependence: an empirical comparison," International Journal of Research in Marketing, vol. 20, no. 1, pp. 87-96, 2003.

[47] C. F. Manski, "The structure of random utility models," Theory and Decision, vol. 8, no. 3, pp. 229-254, 1977.

[48] J. M. Landwehr, N. C. Matalas, and J. R. Wallis, "Probability weighted moments compared with some traditional techniques in estimating Gumbel parameters and quantiles," Water Resources Research, vol. 15, no. 5, pp. 1055-1064, 1979.

[49] J. K. Goeree, C. A. Holt, and T. R. Palfrey, "Quantal response equilibrium and overbidding in privatevalue auctions," Journal of Economic Theory, vol. 104, no. 1, pp. 247-272, 2002. 
[50] G. Cicia, T. D. Giudice, and R. Scarpa, “Consumers' perception of quality in organic food: a random utility model under preference heterogeneity and choice correlation from rank-orderings," British Food Journal, vol. 104, pp. 200-213, 2002.

[51] A. Petrin, "Quantifying the benefits of new products: the case of the minivan," working paper 8227, The National Bureau of Economic Research, 2001.

[52] L. Jongsu, C. Youngsang, L. Jeong-Dong, and L. Chul-Yong, "Forecasting future demand for largescreen television sets using conjoint analysis with diffusion model," Technological Forecasting and Social Change, vol. 73, no. 4, pp. 362-376, 2006.

[53] H. A. Simon, "Bounded rationality and organizational learning," Organization Science, vol. 2, no. 1, pp. 125-134, 1991.

[54] N. Hauenschild and P. Stahlecker, "Nash-equilibria in a heterogeneous oligopoly with fuzzy information," Review of Economic Design, vol. 8, no. 2, pp. 165-184, 2003.

[55] M. Aristidou and S. Sarangi, "Games in fuzzy environments," Southern Economic Journal, vol. 72, no. 3, pp. 645-659, 2006.

[56] I. S. Bakal, J. Geunes, and H. E. Romeijn, "Market selection decisions for inventory models with pricesensitive demand," Journal of Global Optimization, vol. 41, no. 4, pp. 633-657, 2008.

[57] J. V. Neumann, “Zur Theorie der Gesellschaftsspiele," Mathematische Annalen, vol. 100, no. 1, pp. 295 320, 1928.

[58] S. A. Orlovsky, “On programming with fuzzy constraint sets,” Kybernetes, vol. 6, no. 3, pp. 197-201, 1977.

[59] H. Tanaka, T. Okuda, and K. Asai, “On fuzzy mathematical programming," J Cybern, vol. 3, no. 4, pp. 37-46, 1973.

[60] S. M. Gilbert and V. Cvsa, "Strategic commitment to price to stimulate downstream innovation in a supply chain," European Journal of Operational Research, vol. 150, no. 3, pp. 617-639, 2003.

[61] M. S. Bazaraa, H. D. Sherali, and C. M. Shetty, Nonlinear Programming: Theory and Algorithms, John Wiley and Sons, 2006.

[62] Y. J. Lai and C. H. Hwang, Fuzzy Mathematical Programming, Methods and Applications, Springer, New York, NY, USA, 1992. 


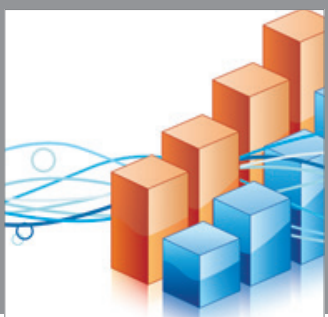

Advances in

Operations Research

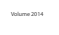

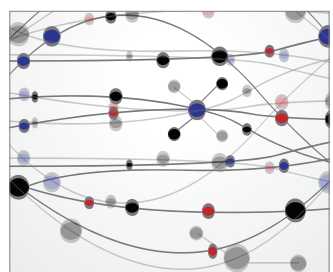

\section{The Scientific} World Journal
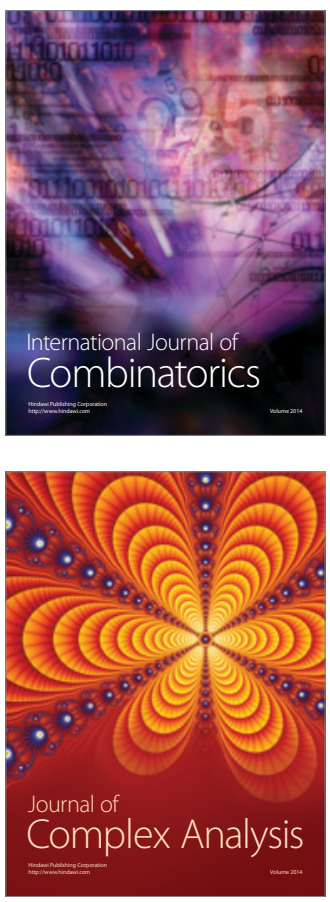

International Journal of

Mathematics and

Mathematical

Sciences
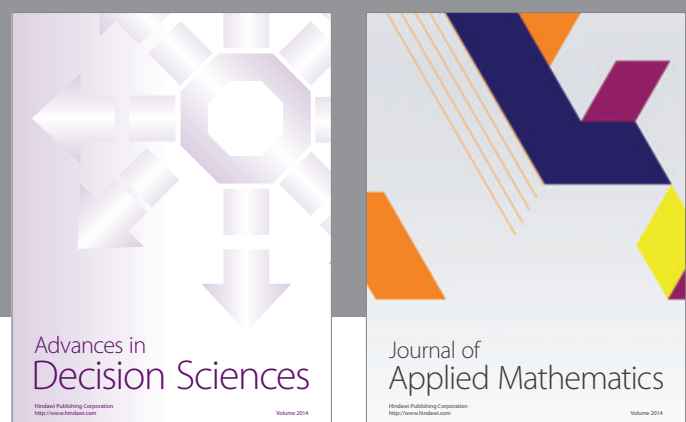

Journal of

Applied Mathematics
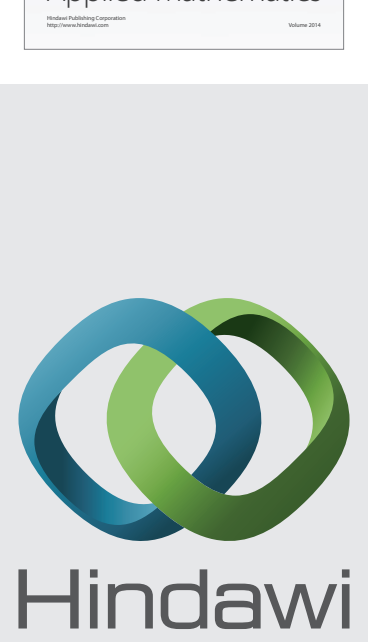

Submit your manuscripts at http://www.hindawi.com
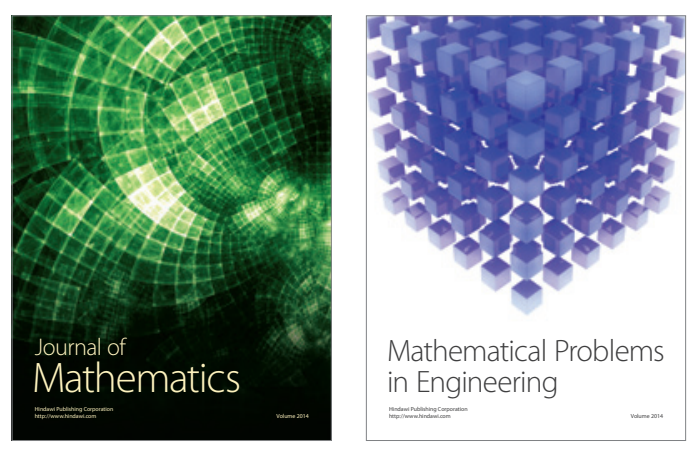

Mathematical Problems in Engineering
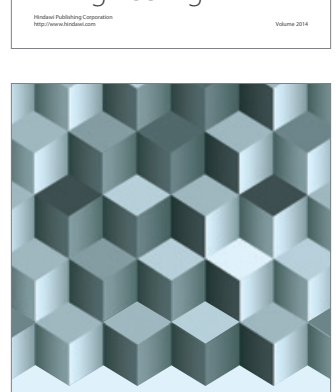

Journal of

Function Spaces
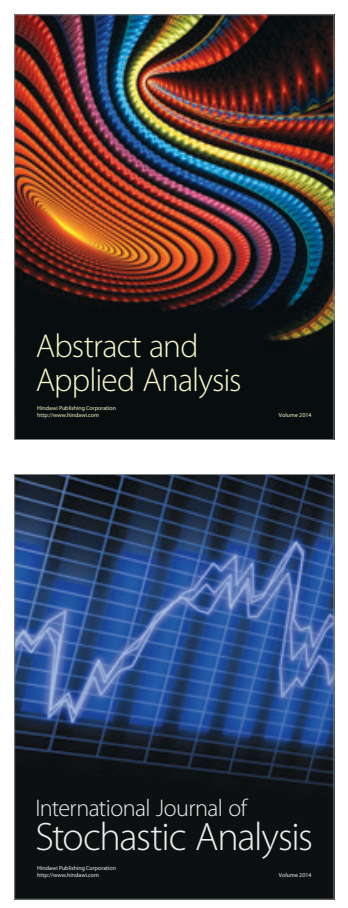

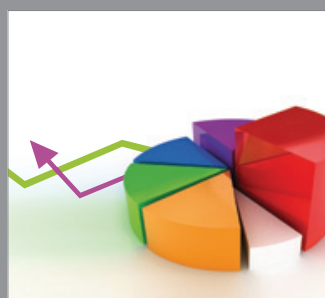

ournal of

Probability and Statistics

Promensencen
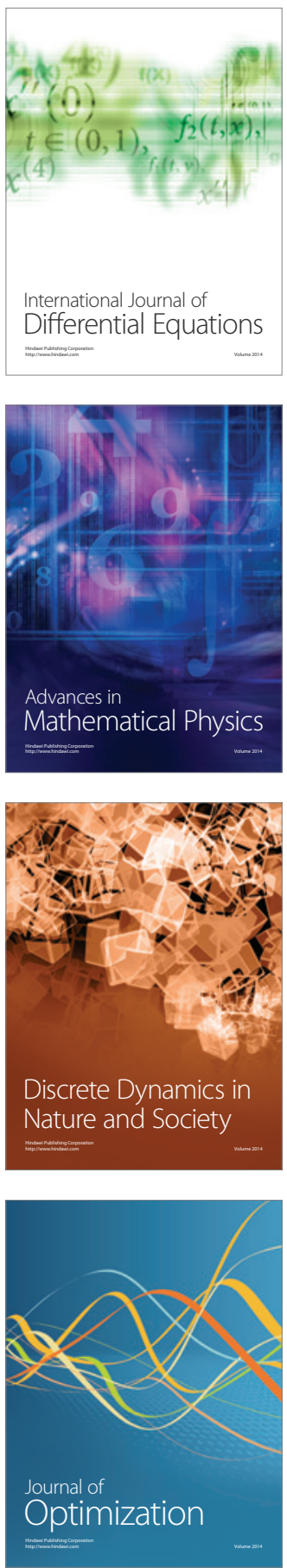